\title{
Onset of meiosis in the chicken embryo; evidence of a role for retinoic acid
}

\author{
Craig A Smith*†1, Kelly N Roeszler ${ }^{\dagger 1}$, Josephine Bowles², Peter Koopman² \\ and Andrew H Sinclair ${ }^{1}$
}

\begin{abstract}
Address: ${ }^{1}$ Murdoch Childrens Research Institute and University of Melbourne Department of Paediatrics, Royal Children's Hospital, Melbourne, 3052, Australia and 2Institute for Molecular Bioscience, University of Queensland, 4072, Brisbane, Australia

Email: Craig A Smith* - craig.smith@mcri.edu.au; Kelly N Roeszler - kelly.roeszler@mcri.edu.au; Josephine Bowles - j.bowles@imb.uq.edu.au; Peter Koopman - p.koopman@imb.uq.edu.au; Andrew H Sinclair - andrew.sinclair@mcri.edu.au

* Corresponding author †Equal contributors
\end{abstract}

Published: 17 September 2008

BMC Developmental Biology 2008, 8:85 doi:10.1186/147/-2/3X-8-85

This article is available from: http://www.biomedcentral.com/I47|-2/3X/8/85

(C) 2008 Smith et al; licensee BioMed Central Ltd.

This is an Open Access article distributed under the terms of the Creative Commons Attribution License (http://creativecommons.org/licenses/by/2.0), which permits unrestricted use, distribution, and reproduction in any medium, provided the original work is properly cited.
Received: 4 April 2008

Accepted: 17 September 2008

\begin{abstract}
Background: Meiosis in higher vertebrates shows a dramatic sexual dimorphism: germ cells enter meiosis and arrest at prophase I during embryogenesis in females, whereas in males they enter mitotic arrest during embryogenesis and enter meiosis only after birth. Here we report the molecular analysis of meiosis onset in the chicken model and provide evidence for conserved regulation by retinoic acid.
\end{abstract}

Results: Meiosis in the chicken embryo is initiated late in embryogenesis (day 15.5), relative to gonadal sex differentiation (from day 6). Meiotic germ cells are first detectable only in female gonads from day 15.5, correlating with the expression of the meiosis marker, SCP3. Gonads isolated from day 10.5 female embryos and grown in serum-free medium could still initiate meiosis at day 16.5 , suggesting that this process is controlled by an endogenous clock in the germ cells themselves, and/or that germ cells are already committed to meiosis at the time of explantation. Early commitment is supported by the analysis of chicken STRA8, a pre-meiotic marker shown to be essential for meiosis in mouse. Chicken STRA8 is expressed female-specifically from embryonic day 12.5, preceding morphological evidence of meiosis at day 15.5. Previous studies have shown that, in the mouse embryo, female-specific induction of STRA 8 and meiosis are triggered by retinoic acid. A comprehensive analysis of genes regulating retinoic acid metabolism in chicken embryos reveals dynamic expression in the gonads. In particular, the retinoic acid-synthesising enzyme, $R A L D H 2$, is expressed in the left ovarian cortex at the time of STRA8 up-regulation, prior to meiosis.

Conclusion: This study presents the first molecular analysis of meiosis onset in an avian embryo. Although aspects of avian meiosis differ from that of mammals, a role for retinoic acid may be conserved.

\section{Background}

One of the most fundamental developmental events in vertebrate embryos is the sexually dimorphic regulation of germ cell fate. In male mammals, the germ cells become incorporated into developing seminiferous cords of the testis during embryogenesis, where they enter mitotic 
arrest as prospermatogonia [1]. This quiescent state is thought to be induced by a signal from the adjacent Sertoli cells of the testis cords [2]. In contrast, germ cells in the female gonad enter the early stages of meiosis during embryonic life, arresting at prophase I as oocytes. Early studies showed that germ cells of either sex can enter meiosis if they migrate to ectopic sites such as the adrenal gland [3] or if isolated and cultured in vitro [4]. A long held view based on these observations was that germ cells enter meiosis cell-autonomously if they do not become enclosed in testis cords, as in males. An alternative possibility is that meiosis is induced, and that the inductive signal in developing ovaries is also present in non-gonadal sites and in culture conditions in vitro. Recent studies have now shown that meiosis is indeed induced in the mouse embryo, and that the inductive signal is retinoic acid $[5,6]$.

A major retinoic acid synthesising enzyme in the mammalian embryo is Raldh2 (Retinaldehyde dehydrogenase, type 2; also called Aldh1a2) [7]. Sites of Raldh2 mRNA expression in the embryo precisely reflect sites of retinoic acid production. In the embryonic mouse urogenital system, Raldh2 mRNA is expressed in the mesonephric kidneys rather than the gonads themselves, and retinoic acid is then thought to diffuse into the neighbouring gonad [5]. Sexual dimorphism in retinoic acid availability, however, is achieved through the differential expression of Cyp26b1, which encodes a major retinoic acid-degrading enzyme. In developing mouse gonads, Cyp26b1 is male up-regulated in the gonads from embryonic day 12.5 , just prior to germ cell mitotic arrest [5,8]. In contrast, Cyp26b1 expression disappears in female gonads at the time of meiosis [5]. This results in the accumulation of retinoic acid in fetal ovaries and the induction of the pre-meiotic protein, Stra8, which is essential for meiosis [9,10]. Male mouse gonads cultured in the presence of retinoic acid show up-regulation of Stra8 and expression of meiosis markers such as Synaptonemal complex 3 (Scp3). Furthermore, meiosis markers are activated in male mouse gonads cultured with CYP enzyme inhibitors such as ketoconazole (retinoic acid is therefore not degraded) or in gonads derived from Cyp26b1 null mutant mice $[5,6,11]$. Conversely, treatment of cultured gonads with a retinoic acid antagonist blocks or retards germ cell meiosis in females $[5,6]$. Altogether, these data indicate that retinoic acid induces meiosis in female mouse gonads, and that meiosis is prevented in male embryos by the degrading enzyme, Cyp26b1.

In this study, we describe the onset of meiosis at the molecular level in an avian model, the chicken embryo. Chicken germ cells originate at an extra-gonadal site and migrate into the gonads via the bloodstream. They settle in the gonads by day 6 of the 21 day incubation period, with more cells populating the left versus the right gonad (in both sexes) [12]. Male germ cells do not proliferate significantly from the time of testicular organization (day 6 onwards), while female germ cells proliferate considerably, from at least as early as day $9[13,14]$. In the female, germ cell fate differs between the left and right gonads. In the left gonad, a thickened outer cortex of somatic cells develops, and nests of synchronously proliferating germ cells become apparent in the left cortex from day 10. It has been estimated that the total population of germ cells in the left ovarian cortex increases about twenty-five fold between day 9 and day 17 of incubation [14]. In contrast, the right gonad fails to proliferate a cortex. Germ cells in the right gonad proliferate somewhat in the underlying medulla, but they later undergo apoptosis [15].

We find that meiosis only occurs in those germ cells located in the left ovarian cortex, from day 15.5 of incubation. The premeiotic marker, STRA 8 , is female up-regulated 2-3 days prior to this time (day 12.5). In addition, we provide evidence that meiosis in birds may also depend upon retinoic acid signalling, as in mouse. In the chicken embryo, RALDH2 is expressed in the gonads themselves, rather than the mesonephric kidneys (as is the case in the mouse). In females, RALDH2 expression is specifically localised in the left gonadal cortex at the time of STRA8 expression, and the cortex is the site of meiosis. CYP26B1 (which degrades retinoic acid) is expressed in both sexes, but not in the outer cortical layer of developing ovaries, where meiosis occurs. In the right female gonad (which lacks a cortex) RALDH2 and CYP26B1 are both expressed in the gonadal medulla, potentially leading to RA synthesis and degradation. These observations suggest a conserved role for retinoic acid in vertebrate meiosis.

\section{Methods \\ Embryos and histology}

Fertile chicken eggs (White Leghorn $\times$ Australop cross) were incubated at $37.8^{\circ} \mathrm{C}$ under humid conditions. Embryos were staged according to the morphological criteria of Hamburger and Hamilton [16], and sexed by PCR, using W (female)-specific Xho1 primers and 18S rRNA primers as internal controls [17]. For histology, urogenital systems were dissected from embryos and fixed in Bouin's solution, followed by dehydration in graded ethanols. Tissues were then infiltrated and embedded in paraffin. Six micron sections were mounted onto gelatin-coated slides and stained with haematoxylin and eosin using standard methods. Germ cells were recognised by their relatively large size and pale cytoplasm. The nuclei of meiotic cells showed condensed, thread-like chromatin.

\section{Whole mount in situ hybridisation}

Whole mount in situ hybridisation was used to examine the expression of genes encoding meiosis markers and 
enzymes involved in retinoic acid production and catabolism. In the mouse, Stra8 (Stimulated by retinoic acid, number 8 ) is a premeiotic marker, and the germ cells of Stra8 null mutant mice fail to enter meiosis [9]. An 816 base pair fragment of the predicted chicken STRA8 sequence (XM_416179) was amplified by PCR, using mixed sex embryonic gonadal cDNA. The $c S T R A 8$ primers were cSTRA8-For: 5'-TATCCAGGAGCTGGAGCAAACC-3' and CSTRA8-Rev: 5'-TCAAAGGTCTCCGTGCACCG-3'. A Chicken 750 bp Synaptonemal Complex protein 3 (SCP3) fragment was PCR amplified from day 16.5 female gonadal cDNA, using the following specific primers: cSCP3-For: 5'-CTCAGCAGCAGATCTTTGCAGC-3' and cSCP3-Rev: 5'-GGTACAAGTTGTTTCTCCATTGAGCC-3'. cDNA clones of chicken RALDH1, RALDH2, RALDH3, CYP26A1, CYP26B1, CYP26C1 were gifts from Malcolm Maden, King's College, London [18]. The identity of clones was confirmed by sequencing.

Whole mount in situ hybridisation was carried out as described previously [19], with some modifications. Briefly, whole urogenital systems were dissected in chilled DEPC-treated PBS, fixed overnight at $4{ }^{\circ} \mathrm{C}$ in $4 \%$ paraformaldehyde (PFA)/PBS and dehydrated in graded methanols on ice. Following rehydration, tissues were incubated in PBS containing 0.1\% Triton X-100 (PBTX), and then permeabilised with a high concentration of proteinase $\mathrm{K}$ in PBTX $(50 \mu \mathrm{g} / \mathrm{mL})$ for 45 to 120 minutes at room temperature. Permeabilisation times varied according to the age of the tissues: embryonic day $8.5-12.5$ urogenital systems were permeabilised for 45-75 minutes, and older tissues, (day 14.5-16.5) were permeabilised for up to 120 minutes. Antisense and sense digoxygeninlabelled riboprobes were synthesised from PCR generated cDNA templates, precipitated and added to tissues equilibrated in prehybridisation buffer. Hybridisation was carried out overnight at $65^{\circ} \mathrm{C}$, following by washing in $2 \times$ SSC/0.1\% CHAPS and $0.2 \times$ SSC/0.1\% CHAPS (30 minutes each at $65^{\circ} \mathrm{C}$ ). Tissues were then pre-blocked in TBTX (50 mM Tris-HCl, pH7.5, $150 \mathrm{mM} \mathrm{NaCl}, 0.1 \%$ Triton X100 ) containing $10 \%$ sheep serum and $2 \%$ BSA (TBTX/ NSS/BSA), then incubated overnight in TBTX/NSS/BSA containing alkaline phosphatase-congujated anti-digoxygenin antibody (1:200). Following extensive washing in TBTX/0.1\%BSA, tissues were incubated in NTMT buffer containing chromogen (BCIP/NBT). Stained tissues were photographed under a Leica MZ8 stereomicroscope. To visualise staining in sections, some tissues were then left in chromogen solution over two days at room temperature, cryoprotected in 30\% sucrose in PBS (overnight at $4^{\circ} \mathrm{C}$ ), snap frozen in OCT embedding compound, cut on a cryostat at $14 \mu \mathrm{m}$ and photographed. When in situ hybridisation was used to compare expression in male and female samples, all tissues were treated in parallel including being stained for the same length of time.

\section{Isolation of RNA and real time PCR (qRT-PCR)}

Real time PCR was used to assess the expression of chicken STRA8, SCP3, RALDH2 and CYP26B1. Pools of paired gonads were dissected from staged embryos over embryonic days 6.5 to 16.5 and total RNA was extracted using Trizol ${ }^{\oplus}$ reagent (Invitrogen). Ten micrograms of RNA was firstly treated with DNase1 using DNA-Free (Ambion) and $1 \mu \mathrm{g}$ was then reversed transcribed using random hexamers together with oligo $\mathrm{dT}$ as primers. All samples included RT minus reactions to control for contaminating genomic DNA. For real time PCR, $1 \mu \mathrm{l}$ (50 ng cDNA) was used in each reaction. All PCRs were carried out according to standard protocols. Real time PCR was performed using the Universal Probe Library (UPL) system and Faststart Taq Probe Master mix with ROX (Roche). This method involves the generation of standard curves for each primer pair, to test and account for variations in primer efficiency. Fifty nanograms of cDNA was subject to amplification using an ABI 7900 HT Real Time PCR machine. Individual samples were analysed in triplicate and experiments performed twice. All samples were normalised against HPRT using the comparative $\mathrm{C}_{\mathrm{T}}$ method $\left(\Delta \Delta \mathrm{C}_{\mathrm{T}}\right)$. Results were plotted as percentage of maximum expression+/- SEM. Standard curves were constructed for each gene and high PCR efficiency ( $>0.90 \%$ ) was confirmed. Cycle parameters and primers for real time PCR primer/UPL probe set combinations used are included in the supplementary information.

\section{Immunofluorescence}

Immunofluorescence was performed as described previously [20]. Most tissues were fixed in $1 \%$ or $4 \%$ paraformaldehyde in PBS at room temperature for 10-20 minutes, cryoprotected in $30 \%$ sucrose/PBS overnight at $4{ }^{\circ} \mathrm{C}$, immersed in OCT embedding compound and snap frozen. Ten micron frozen sections were permeabilised in $1 \%$ Triton X-100/PBS for 10 minutes. In the case of SYN/ COR staining, unfixed frozen sections were postfixed with $-20^{\circ} \mathrm{C}$ methanol for 10 minutes. All sections were then blocked for 1 hour in 2\% BSA/PBS. Primary antibodies were diluted in $1 \%$ BSA/PBS and added overnight at $4{ }^{\circ} \mathrm{C}$. Rabbit anti- SYN/COR antibody, a marker of meiosis, was obtained from Barbara Spyropoulos and Peter Moens, (York University, Toronto) and was used at 1:500. Rabbit anti-chicken RALDH2 antibody was obtained from Dr. Shan Sockanathan (Johns Hopkins University Medical School, Baltimore) and used at 1:500. Rabbit anit-SPC3 was obtained from Novus Biologicals (1:500). Alexa Fluor secondary antibodies were obtained from Molecular Probes Inc. and used at 1:500 - 1:1500. Sections were routinely counterstained with the nuclear stain, DAPI (300 $\mathrm{nM}$ ). Negative control sections were incubated with preimmune serum instead of primary antibody, or with secondary antibody alone. In all such cases, no specific staining was observed. 


\section{Organ culture}

To study meiosis in vitro, individual gonads (left ovaries or testes), with or without the mesonephros, were explanted at embryonic day 10.5 (stage 36). Tissues were placed onto $5 \mu \mathrm{m}$ isopore filters (Millipore), floating on $500 \mu \mathrm{L}$ of culture medium. The culture medium was either serumsupplemented (DMEM $+10 \%$ foetal calf serum $+2 \%$ chick serum) or serum deprived (DMEM + insulin transferrin, sodium selenium supplement (ITS)). Ampicillin $(50 \mu \mathrm{g} / \mathrm{mL})$ was added to all cultures, and fresh medium was added daily. After 6 days in culture at $37^{\circ} \mathrm{C} / 5 \% \mathrm{CO}_{2}$, tissues were fixed in 4\% paraformaldehyde in PBS (30 minutes at room temperature), cryoprotected overnight in $30 \%$ sucrose/PBS, and $10 \mu \mathrm{m}$ frozen sections cut for immunofluorescence as described above.

\section{Results \\ Histological and molecular characterisation of meiosis onset in the chicken embryo}

The onset of meiosis in the chicken embryo was assessed histologically by haematoxylin and eosin (H \& E) staining of serial sections through the developing gonads. Embryonic chicken gonads of both sexes initially comprise two regions, an inner layer of somatic cell cords (the medulla) and an outer epithelial layer, the cortex. The germ cells migrate into the gonads prior to gonadal sex differentiation. They are scattered throughout the gonad, but are more prevalent in the outer cortical layer. During male development, the inner medulla gives rise to seminiferous cords in both gonads. In female embryos, the outer cortical layer of the left gonad thickens and germ cells accumulate there, while the right gonad fails to proliferate a cortex and germ cells remain scattered in the medulla [21]. Gonadal sex differentiation begins at embryonic day 6.0 (stage 29) [22]. However, in the study described here, the first signs of meiosis were not detected until much later in development. Meiosis was only seen in female gonads, with morphological evidence of meiosis first detectable in the outer layer (cortex) of developing left ovaries at day 15.5 (stage 41). Germ cells were recognised by their large size $(\geq 20 \mu \mathrm{m})$ and pale cytoplasm relative to somatic cells. Meiotic germ cells were distinguished by the presence of condensed thread-like chromatin, as shown in Fig. 1. At day 16.5 (stage 42), meiotic germ cells were more numerous and, by day 18.5 (stage 44) they were abundant in the left gonad. In contrast, germ cells in the right gonad did not exhibit meiotic figures (Fig. 1). No meiotic germ cells were detected in the developing testes of male embryos, as assessed by H\&E staining (Fig. 1).

The sex-specificity of meiosis was confirmed by immunofluorescent detection of synaptonemal complex 3 (SCP3), a meiosis structural protein that was expressed in female but not male embryonic gonads (Fig. 2). In females, germ cells were detected in the cortex of the left gonad and scattered in the medulla of the right gonad at day 14.5 , as assessed by immunoreactivity to GCNA, a cell surface germ cell marker (Fig. 2). A small number of GCNA positive cells in the developing cortex became SCP3 positive at day15.5, and, by day 16.5, SCP3 protein expression was widespread (Fig. 2). In contrast, germ cells scattered in the right female gonad initially expressed GCNA but not SCP3 protein, indicating that germ cells of the right gonad do not enter meiosis. GCNA expression was gradually lost in the right gonad. Male gonads were positive for GCNA but not SCP3 protein (Fig. 2). The SCP3 staining was corroborated by independent staining for SYN/COR, another meiosis marker (not shown). SCP3 expression was also examined at the transcriptional level by whole mount in situ hybridisation and quantitative (real time) RT-PCR (Fig. 3). SCP3 transcripts were first detected by in situ hydridisation at day 15.5, consistent with the histology, indicating meiosis onset at this time. However, expression was observed in both sexes, but was stronger in females (Fig. 3). Sections of over-stained whole mounts revealed SCP3 mRNA in the outer cortical region of the left ovary, the site of meiosis, in agreement with SCP3 protein immunofluorescence. In the right female gonad, SCP3 mRNA expression was distributed throughout. In sectioned males whole mounts, SCP3 mRNA was detectable in the seminiferous cords of both gonads from day 15.5 (Fig. 3). Expression of SCP3 mRNA in both sexes was confirmed by qRT-PCR. Expression was low in males, but became elevated in females during meiosis. (Fig. 3B). However, in males, no SCP3 mRNA was protein was detected (refer to Fig. 2). Taken together with the immunofluorescence results, these data indicate that SCP3 mRNA is expressed in both sexes, but more highly in females, while the transcript is only translated in meiotic cells that is, in germ cells of the left ovarian cortex.

\section{Chicken STRA8 expression}

A critical gene involved in the induction of meiosis in mammals is Stra8 (Stimulated by retinoic acid, \#8) [9]. STRA8 is considered to be a pre-meiotic germ cell marker. Analysis of avian STRA8 has not hitherto been reported. Cloning and analysis of chicken STRA 8 revealed female specific expression in the developing left ovary that preceded the onset of meiosis at the histological level (Fig. 4). In female embryos, STRA8 mRNA expression was first detectable in the left gonad by whole mount in situ hybridisation at day 14.5 (stage 40), one day prior to the onset of meiosis at day 15.5 (stage 41). Using whole mount in situ hybridisation, No STRA8 mRNA was detected in male gonads at any stage examined (day 6.5 day 16.5). In tissue sections of over-stained whole mounts, STRA 8 mRNA was localised in the left ovarian cortex (Fig. 4), the site of meiosis as demonstrated by histology and SCP3 staining. No STRA8 expression was detectable in the right female gonad, consistent with the 


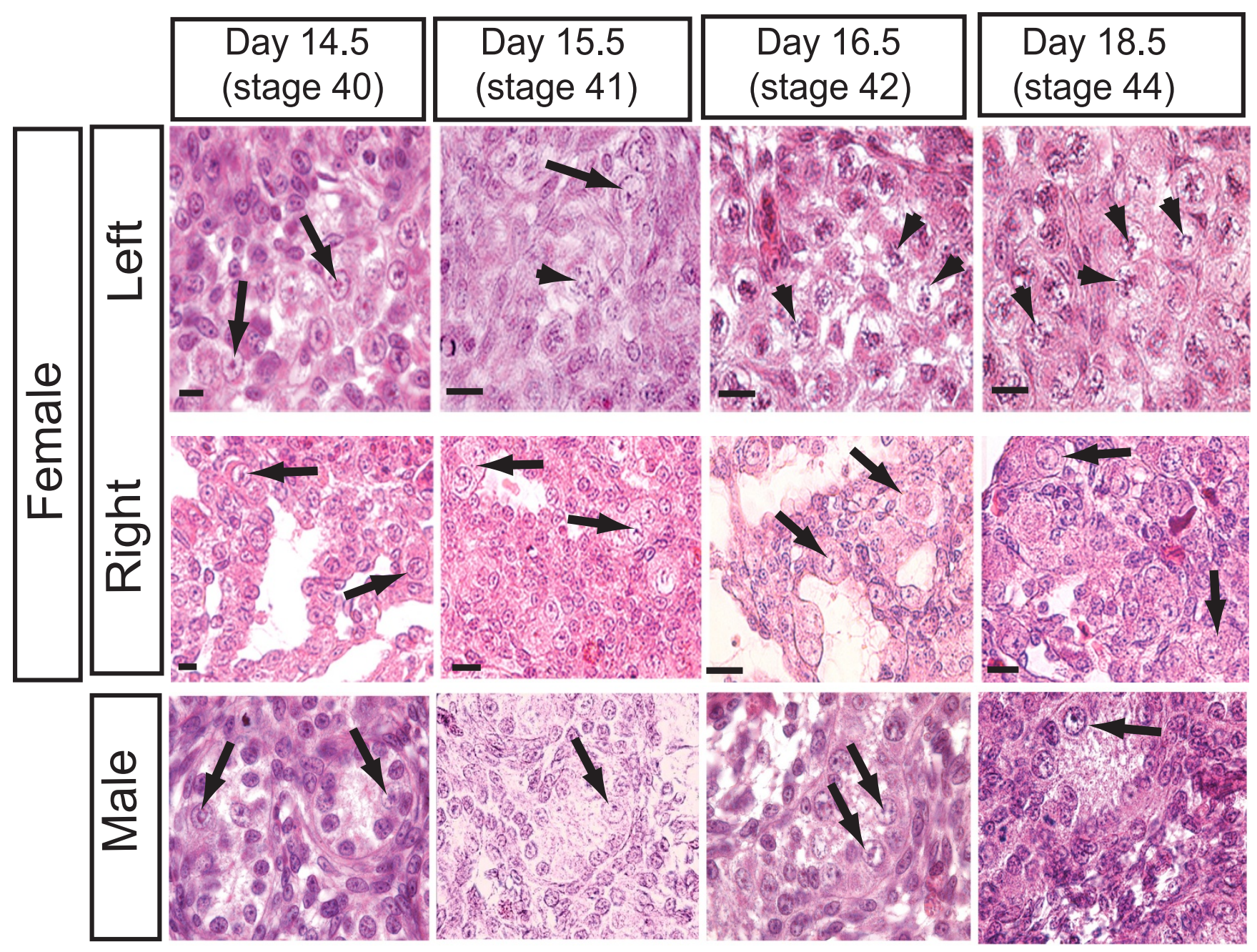

Figure I

Timing and morphology of meiosis in embryonic chicken gonads, assessed by haematoxylin and eosin staining. Arrows indicate non meiotic germ cells; arrowheads indicate meiotic germ cells. At day I4.5 (stage 40) non-meiotic germ cells are present in the gonads of both sexes, recognised by their large size and pale cytoplasm. Meiotic figures are first seen in some germ cells of left female gonads at day I5.5 (arrowheads). The chromatin becomes condensed and threadlike. By day 18.5, most germ cells are meiotic in the left female gonad. In the right female gonad and in both male gonads, only non-meiotic germ cells are present throughout development. Scale bar $=20 \mu \mathrm{m}$.

lack of meiosis there (Fig. 4). Quantitative RT-PCR (qRTPCR) confirmed elevated STRA8 mRNA expression in female gonads. (Both left and right gonads were pooled and assayed together.) By qRT-PCR, female up-regulation of STRA8 was first detectable at day 12.5 (stage 38) (Fig. $4 \mathrm{~B})$. These results indicate that STRA 8 is a premeiotic marker in the chicken, as in mouse.

\section{Meiosis in vitro}

To determine whether germ cells could initiate meiosis in vitro, urogenital systems (gonads+mesonephric kidneys) were excised from embryos and cultured in vitro for up to 6 days. Gonads were then assayed for expression of the meiosis marker protein, SCP3. Gonads explanted on day
10.5 or 12.5 and cultured to E16.5 in the presence or absence of serum could initiate meiosis in vitro (Fig. 5). $\mathrm{GCNA}^{+}$germ cells in female gonads were also largely SCP3 positive. Germ cells in male gonads were SCP3 negative, as in vivo (not shown). Induction of meiosis in basal, serum-free medium, and hence in the absence of any exogenous signaling or growth factors, indicates that female germ cells may enter meiosis cell autonomously, or that the cells are committed to the female pathway by the time of explantation, that is, day 10.5. The latter implies that a signal for meiosis is activated at or before E10.5. Attempts were made to culture gonads from younger embryos (day 6.5 or day 9.5) but extensive germ cell loss occurred. 


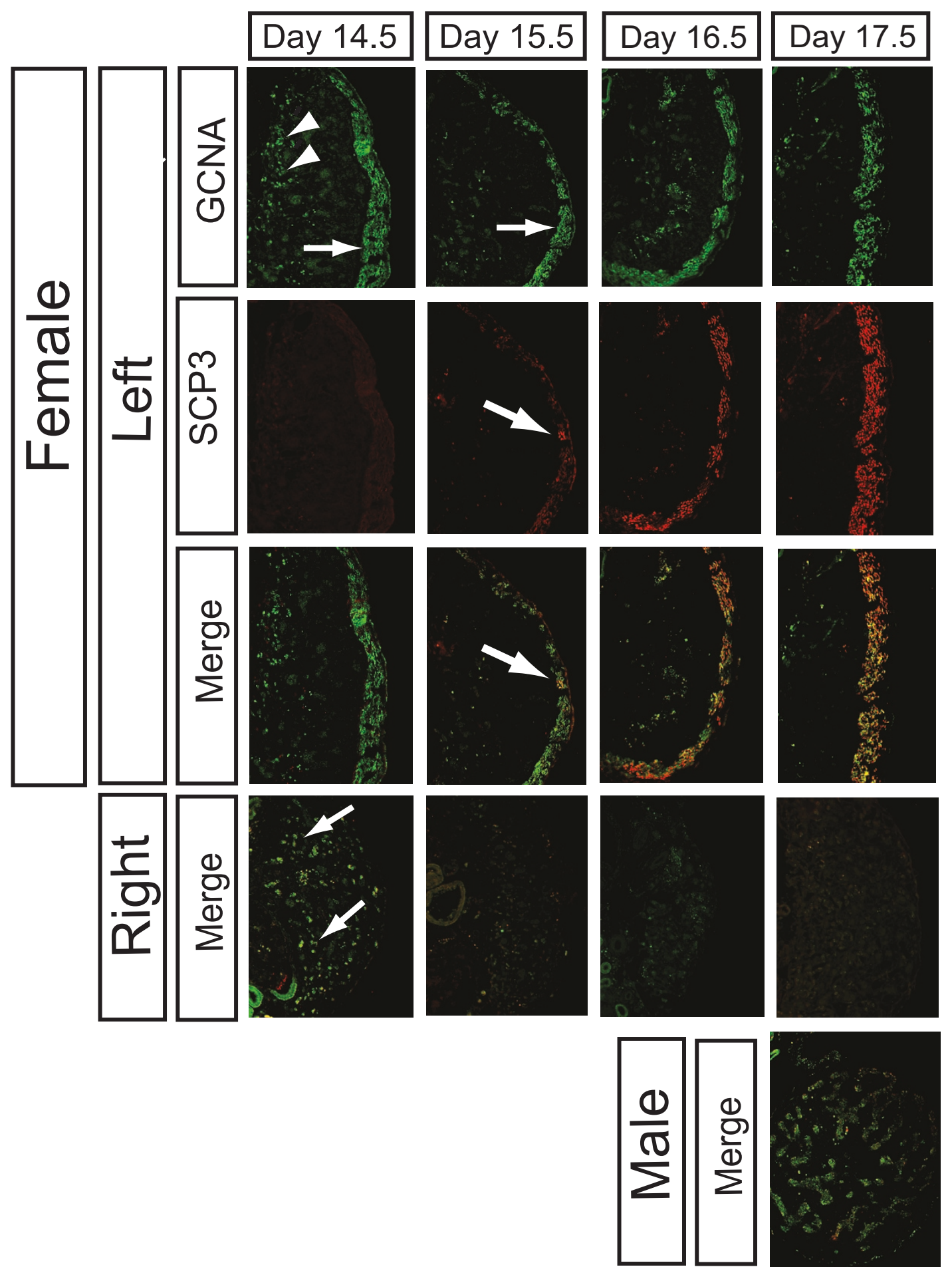

Figure 2

Expression of Synatonemal Complex 3 protein (SCP3) in embryonic chicken gonads, assessed by immunofluorescence. Germ cells are recognised by their immunoreactivity to GCNA antibody (green). In the left female gonad, most germ cells are concentrated in the outer cortex (arrows), but some are present in the inner part of the medulla (arrowheads). Some SCP3 positive cells (red) are first detectable in the cortex of the left female gonad at day I5.5 (arrow), increasing in number up to day 17.5. No SCP3 positive cells are detectable in the left medulla, the right gonad, or in male gonads. In the right female gonad, GCNA staining (green; arrows) is gradually lost after day 14.5. 


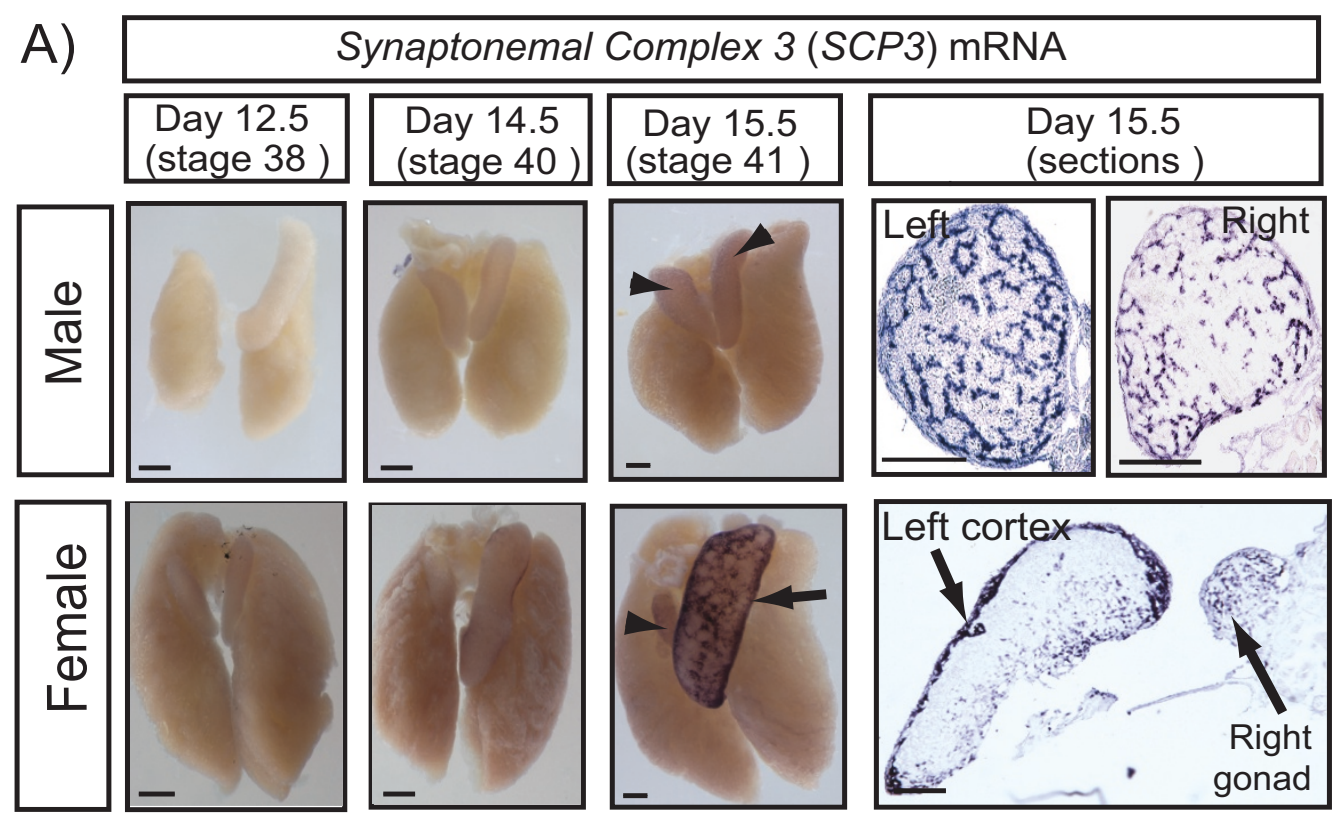

B) Quantitative RT-PCR

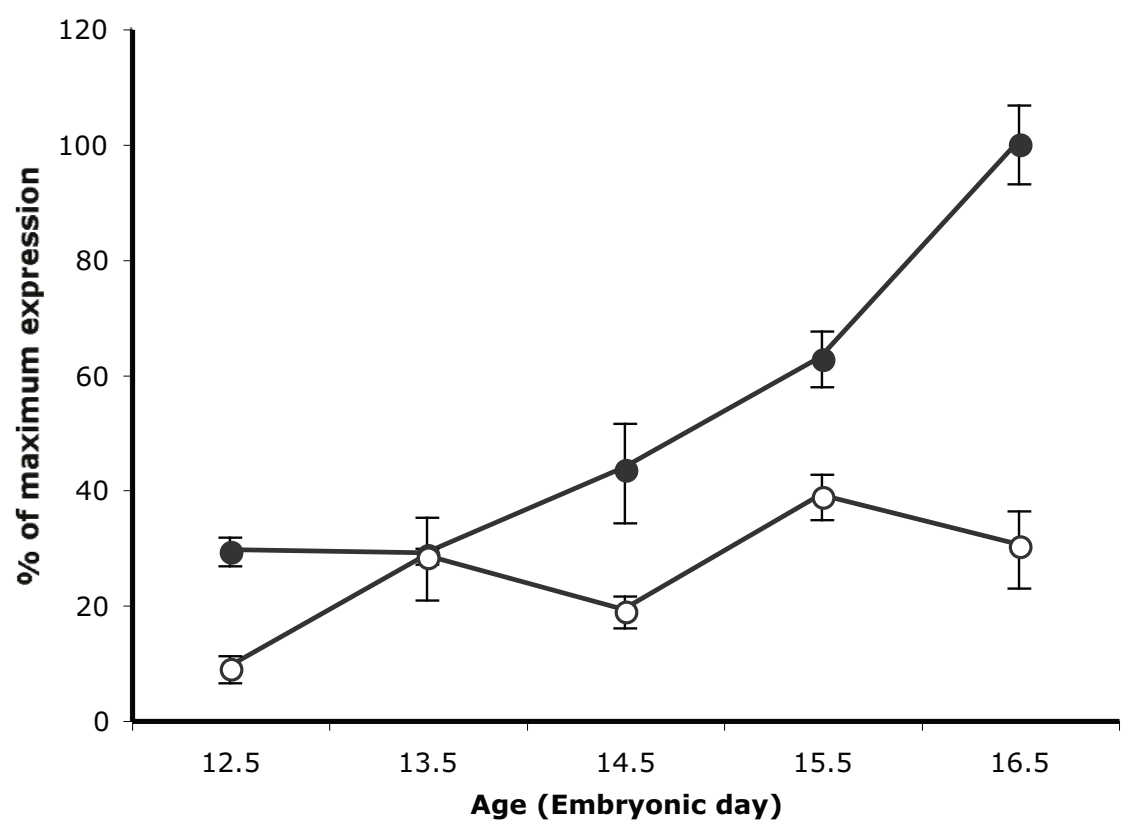

Figure 3

Expression of SCP3 mRNA in embryonic chicken gonads. A) Whole mount in situ hybridisation. Strong SCP3 mRNA expression is seen in the left and right female gonads from day 15.5 (arrow and arrowhead). A lower level of expression is detectable in male gonads at the same time (arrowheads). Over-stained and sectioned whole mounts show bilateral expression in the seminiferous cords of developing testes. In females, mRNA expression is localised to the cortex of the left gonad, and in scattered cells of the left and right medulla. Scale bar on whole mounts $=1 \mathrm{~mm}$, scale bar on sections $=100 \mu \mathrm{m}$. B) Quantitative real time PCR (qRT-PCR) for SCP3 mRNA expression. A low level of expression is detectable in male gonads throughout development (open circles), while expression increases in female gonads during the time of meiosis (closed circles). 
(A)
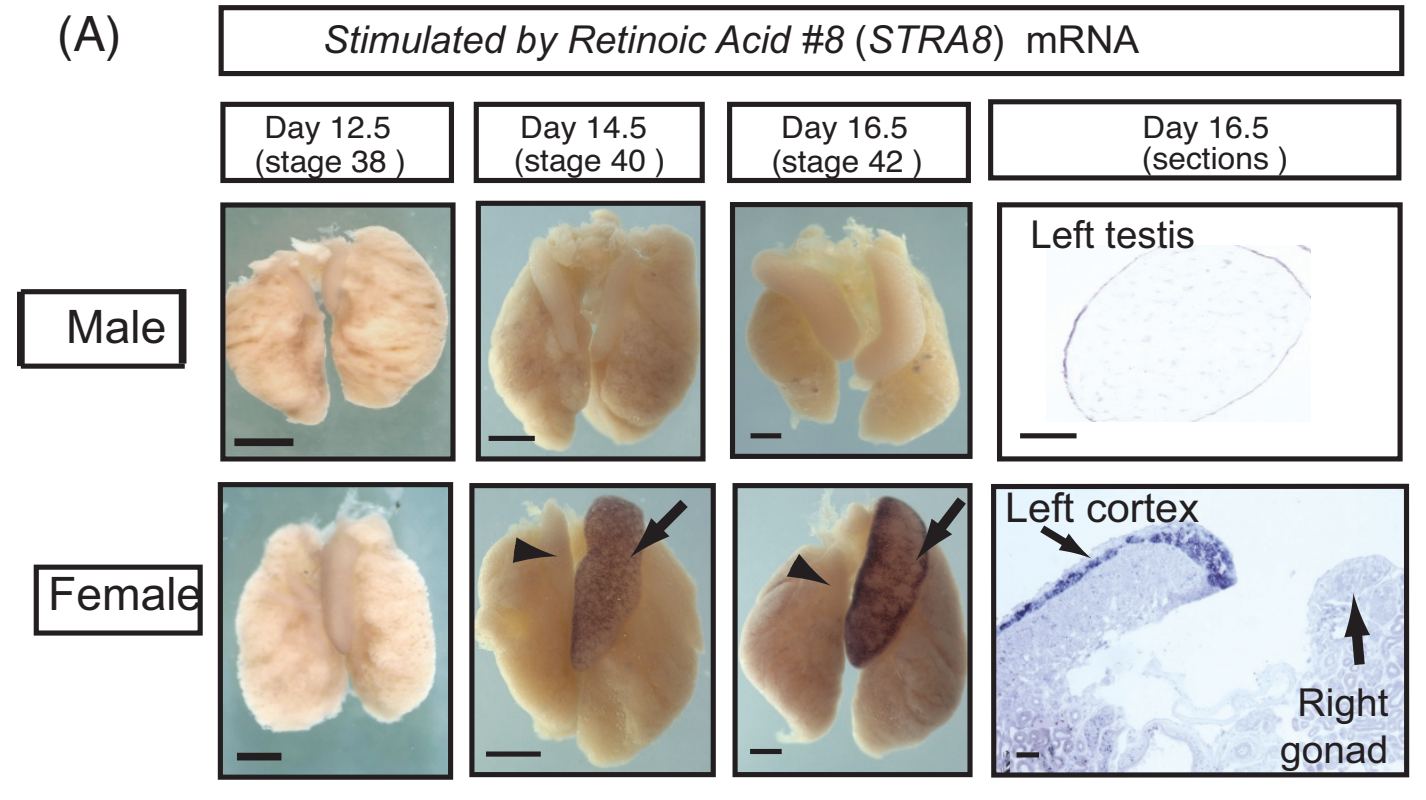

(B)

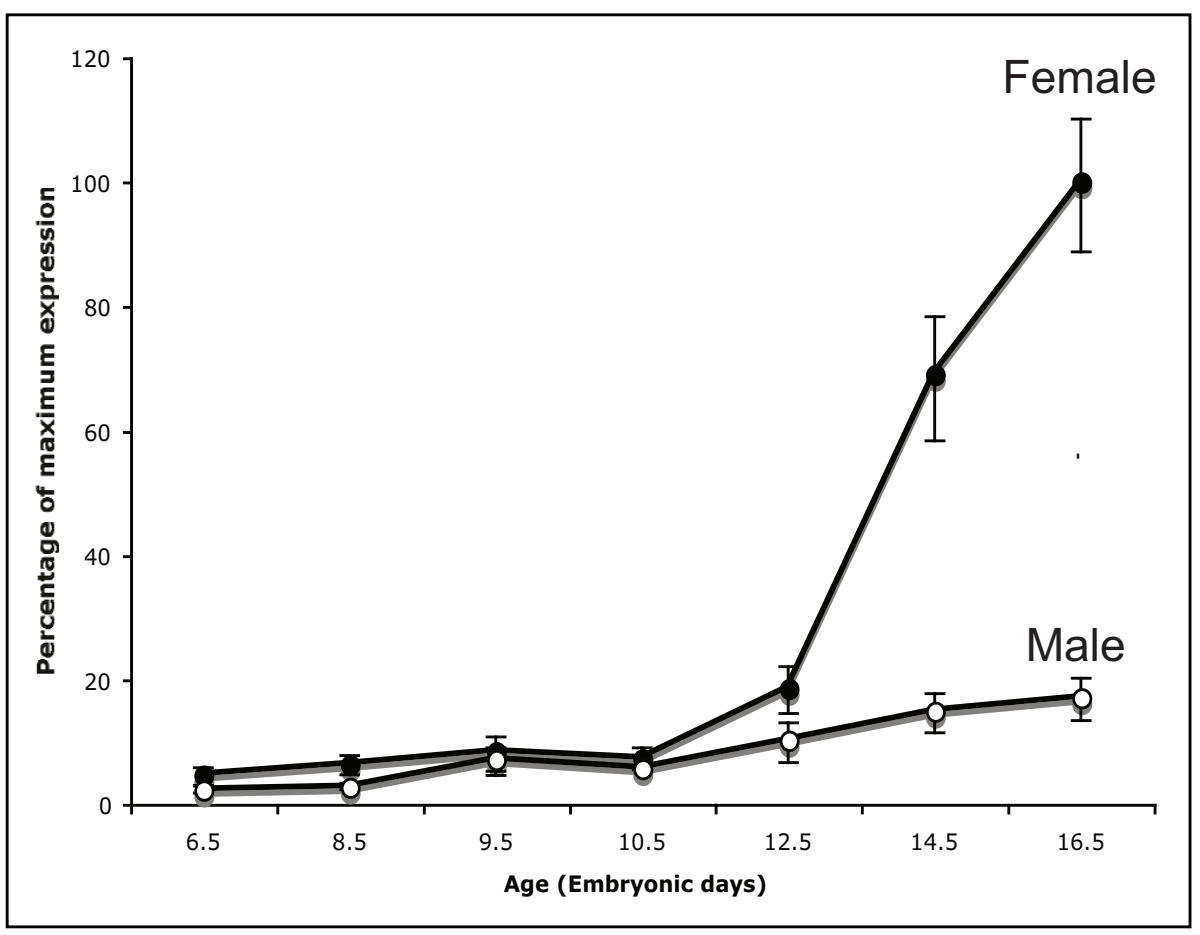

Figure 4

STRA8 mRNA expression in embryonic chicken gonads, as assessed by whole mount in situ hybridisation and quantitative real time PCR (qRT-PCR). (A) In females, expression is specific to cortex of the left gonad, and is first detectable by whole mount in situ hybridisation at day 14.5. No STRA8 mRNA expression is detectable in male gonads. Scale bar in whole mounts $=1 \mathrm{~mm}$, scale bar in tissue sections $=100 \mu \mathrm{m}$. (B) STRA8 qRT-PCR. STRA8 is up-regulated female-specifically from day 12.5. A low level of expression is detectable in male gonads throughout development. Mean +/- SEM. 

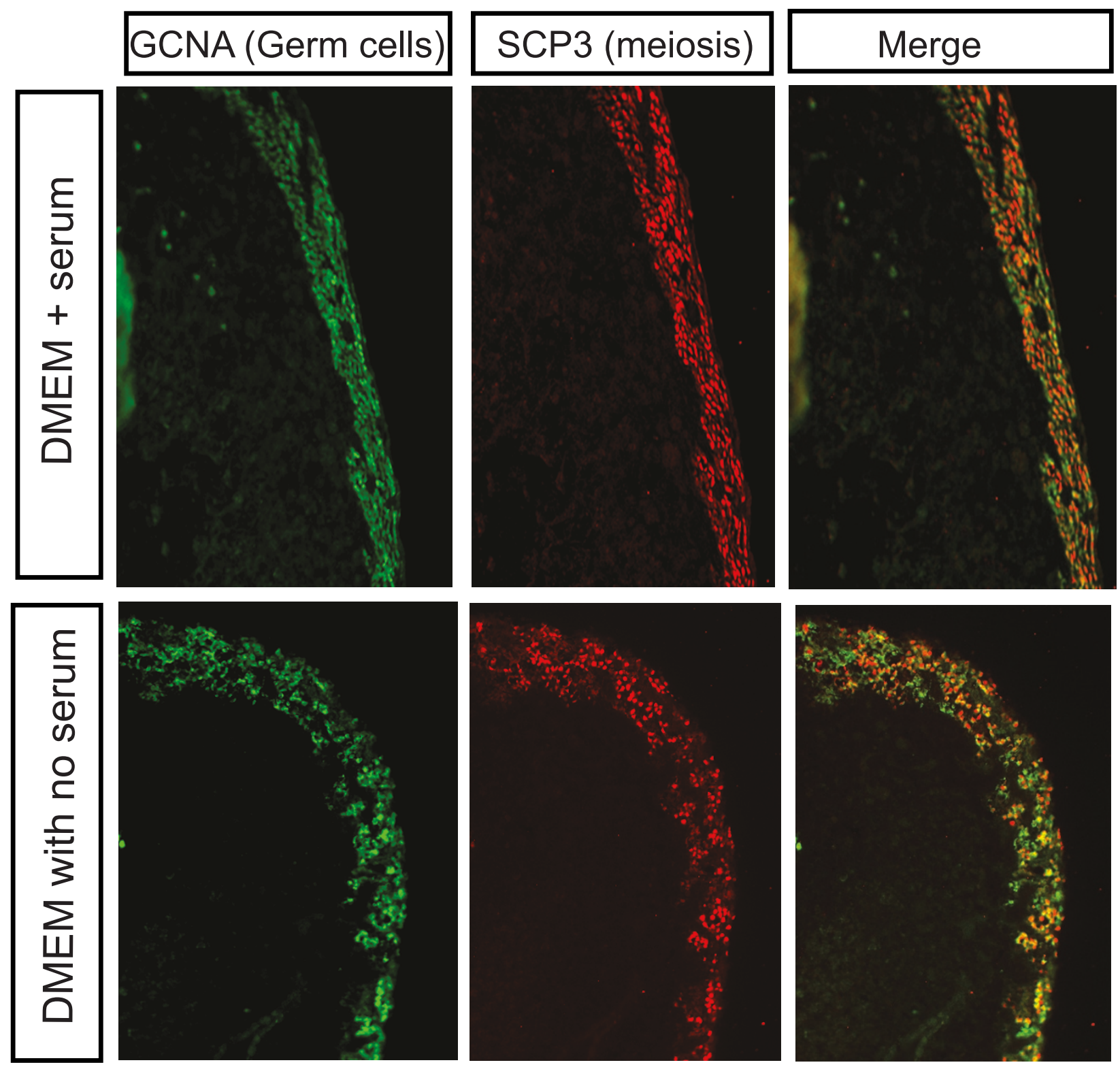

Figure 5

Meiosis in female chicken embryonic gonads in vitro. Day 10.5 embryonic gonads were explanted and grown in the absence or presence of serum (DMEM+ 10\% FCS, $2 \%$ chick serum). After six days in culture, meiosis occurred normally in the developing cortex, as assessed by SCP3 immunofluorescence (red) in GCNA+ germ cells (green).

\section{Dynamic regulation of retinoic acid metabolism in the embryonic gonads}

We next examined the expression of enzymes responsible for retinoic acid production in embryonic chicken gonads to test for a possible conserved role in regulating meiosis. Retinoic acid synthesis in vertebrate embryos is tightly regulated by the tissue specific expression of three synthetic enzymes, RALDH1, RALDH2 and RALDH3. The expression of these enzymes is coordinated with specific expression of three retinoic acid-degrading enzymes, CYP26A1, CYP26B1 and CYP26C1. RALDH2 is the major enzyme catalysing retinoic acid synthesis in the avian 
embryo, and sites of RALDH2 gene expression correlate with retinoic acid production and release [23]. We found that, in embryonic chicken urogenital systems, RALDH2 mRNA was robustly expressed in the gonads of both sexes at all stages examined, including the period of meiosis in females (Fig. 6A). Little if any RALDH2 expression was detected in the adjoining mesonephric kidneys. Gonadal RALDH2 mRNA was detectable by whole mount in situ hybridisation as early as day 6.5 (onset of gonadal sex differentiation) through to at least day 16.5. In sections of over-stained male gonads, RALDH2 expression was present in the developing seminiferous cords of the medulla (Fig. 6B). In females, RALDH2 expression was initially localised in the medulla of early embryos, but then declined in the medulla and became concentrated in the proliferating cortex at day 10.5, that is, at the onset of STRA8 up-regulation (Fig. 6B). This suggests a potential role in STRA8 induction. RALDH2 expression was maintained in the medulla of the right female gonad throughout development (no cortex forms). Real time RT-PCR confirmed robust RALDH2 mRNA expression in both sexes, but with higher expression males (data not shown).

To confirm the expression pattern of RALDH2, a chickenspecific antibody was used to localise the protein in day 14.5 gonads. Immunofluorescence confirmed RALDH2 expression in the Sertoli cells of seminiferous cords in the developing testis (Fig. 7). Most germ cells in seminiferous cords were RALDH2 negative, although double labelling with anti-GCNA and anti-RALDH2 suggested some colocalisation (Fig. 7). Similarly, in day 12.5 and 14.5 female gonads, RALDH2 protein was localised in the somatic (pre-follicular) cells of the ovarian cortex (Fig. 7C and 7D). In females, RALDH2 protein did not co-localise with either GCNA or SOX2, both germ cell markers (Fig. 7C and 7D). Double staining for the somatic marker, GATA4, and RALDH2 delineated somatic cells of the ovarian cortex with RALDH2+ cytoplasm and GATA4+ nuclei (Fig. 7E). These data indicate that the somatic cells (Sertoli cells of males and cortical pre-follicular cells of females) have the capacity to synthesise retinoic acid.

The key retinoic acid-degrading enzyme, CYP26B1, showed sexually dimorphic expression in embryonic gonads that correlated with the onset of meiotic prophase in females (Fig. 8). CYP26B1 mRNA was initially detectable in the gonads of both sexes at least as early as day 8.5 (stage 33), well prior to meiosis. Expression was maintained in males, but declined in females at the time of meiosis (Fig 8A). In sections of over-stained tissues, CYP26B1 mRNA was localised in the seminiferous cords, that is, in the same location as RALDH2 expression (Fig $8 \mathrm{~B})$. The pattern and extent of staining indicated expression at least in Sertoli cells. In female sections, CYP26B1 showed an intriguing profile. The gene was initially expressed in the gonadal medulla, as in males, but expression became progressively restricted to the juxtacortical medulla (JCM), adjacent to the cortex, and then declined (Fig. 8B). The developing cortex itself did not show CYP26B1 expression at any stage (Fig. 8B). Taken together with the RALDH2 data, these observations indicate that the developing ovarian cortex - the site of germ cell meiosis - has the capacity to synthesise retinoic acid, but does not express the retinoic acid-degrading enzyme, CYP26B1. In the right female gonad, CYP26B1 expression was localised to the medulla throughout development (Fig 8B), consistent with the absence of STRA8 expression in this location. Analysis of gonadal CYP26B1 by qRT-PCR suggested higher expression in males compared to females from early in development (from day 6.5) (Fig. 9A). This may reflect legitimate up-regulation in males as a result of male somatic commitment, or it may reflect the progressive restriction of expression in females, so that CYP26B1+ cells comprise a progressively smaller component of the growing ovary (see the restricted expression of CYP26B1 in later stage females is Fig 8B). When female CYP26B1 and STRA8 expression profiles are analysed together, an inverse relationship is apparent (Fig 9B). As CYP26B1 mRNA levels decline from day 10.5, STRA8 levels begin to increase, suggesting that an accumulation of retinoic acid may lead to STRA8 induction.

Expression profiles of the other retinoic acid metabolising enzymes were also studied, using whole mount in situ hybridisation for chicken RALDH1, RALDH3, and CYP26A1 and CYP26C1 (Table 1). RALDH1 was expressed only in male gonads at all stages examined, from day 6.5 (stage 30) through to day 16.5 (stage 42). Similarly, RALDH3 was expressed male-specifically, but in a more temporally defined pattern, from E8.5 to E12.5. Only $R A L D H 2$, therefore, was expressed in the gonads of both sexes throughout development, including the time of meiosis induction in females. The other CYP26 mRNAs showed female biased expression in young gonads, but CYP26A1 and CYP26C1 were not expressed in the gonads of either sex from day 8.5 (Table 1). This excludes these enzymes as mediators of retinoic acid degradation during most of gonadal development. The only CYP26 mRNA showing a sexually dimorphic expression profile consistent with a role in meiosis was therefore CYP26B1 (Table $1)$. We also examined expression of the retinoic acid receptor $\beta$ gene (Figure 10). Whole mount in situ hybridisation showed that RAR $\beta$ was expressed in the gonads of both sexes throughout development. However, in the female, expression declined in the right gonad, from day 14.5 (Fig. 10; arrows).

\section{Discussion}

This study provides the first molecular analysis of meiosis onset in an avian species, and presents evidence of a con- 


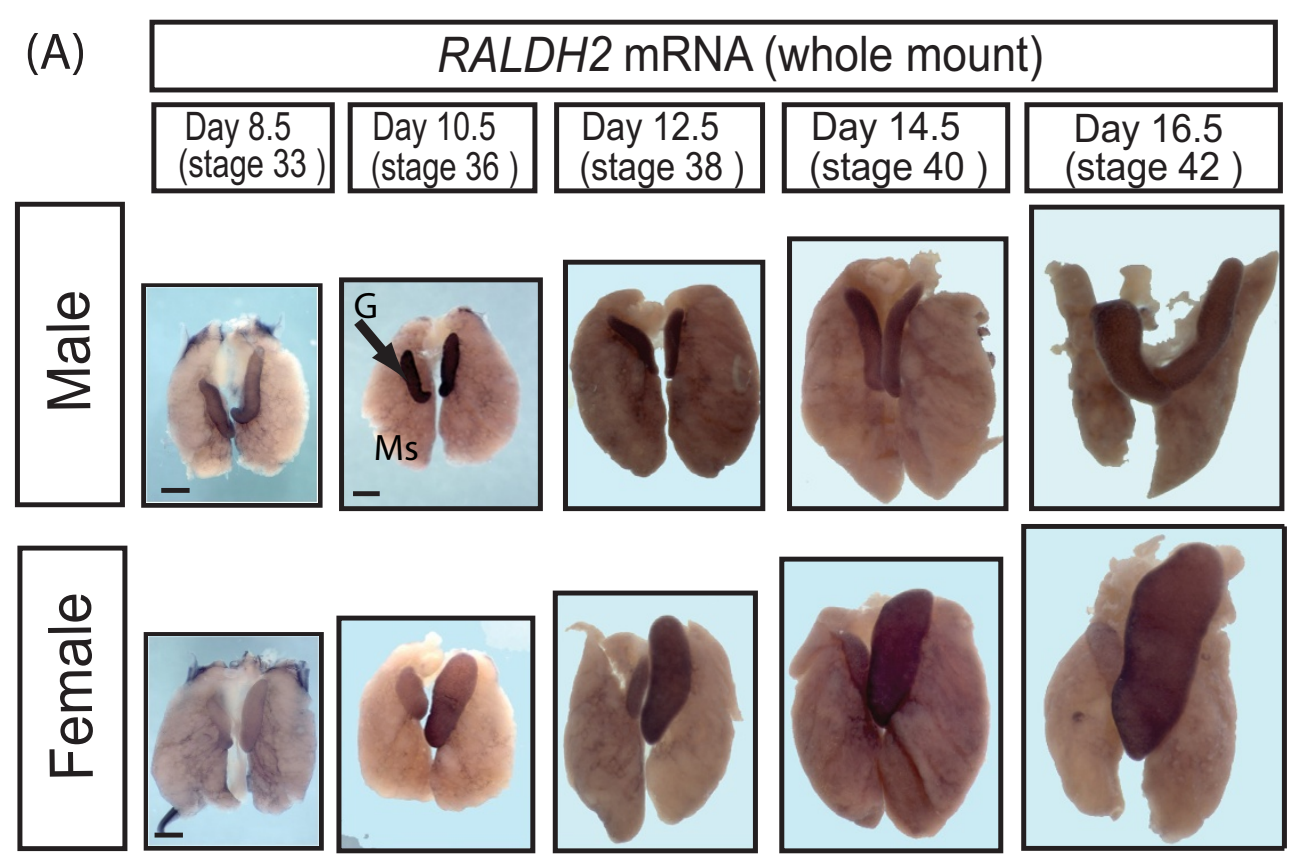

(B)
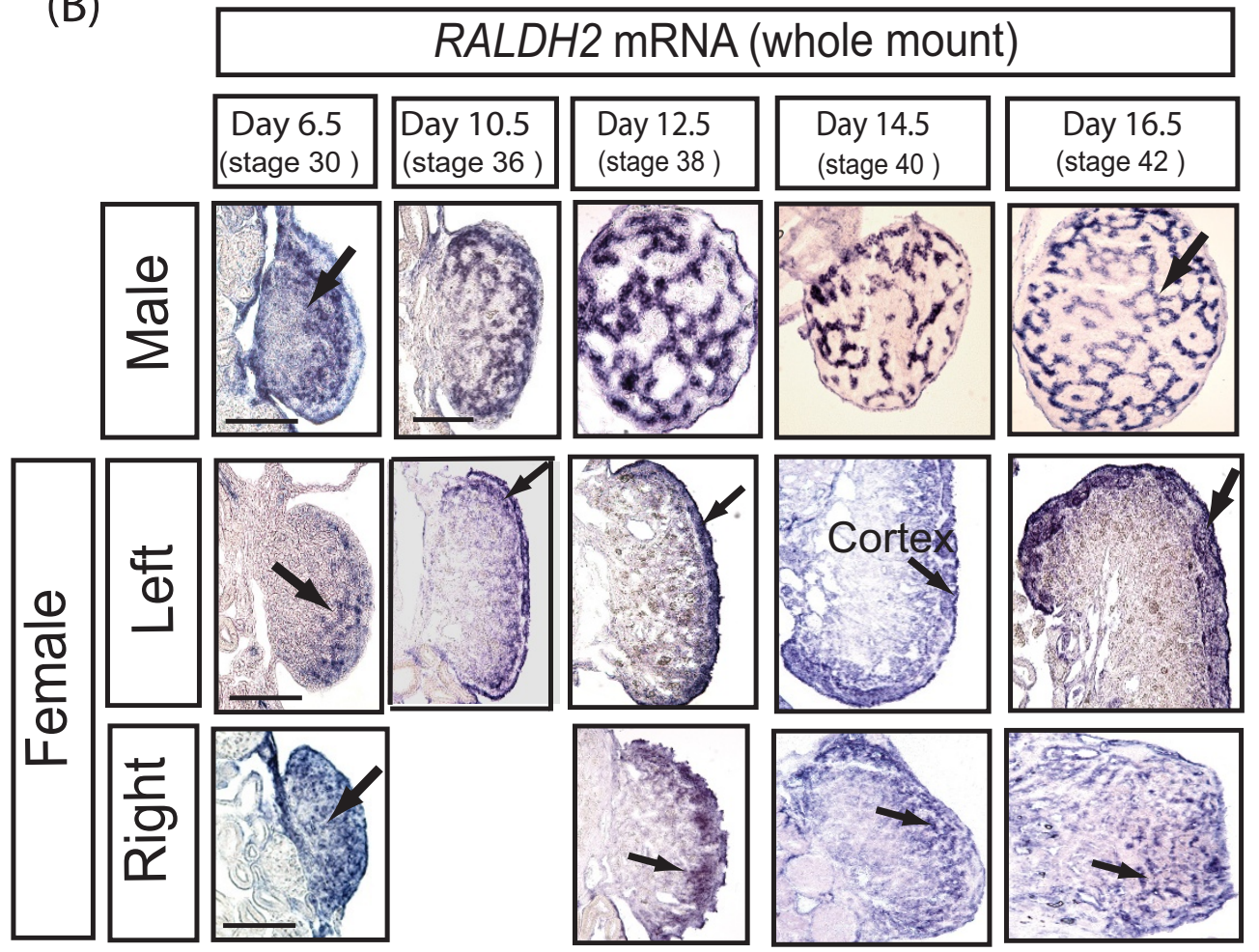

Figure 6

Expression of RALDH2 mRNA in embryonic chicken gonads, as assessed by whole mount in situ hybridisation. (A) In both sexes, expression is detectable in both gonads throughout development (e.g, $G$ ). There is no significant expression in the mesonephric kidneys (eg. Ms). (B) In males, RALDH2 expression localises to the seminiferous cords. In females, expression becomes localised in the proliferating cortex of the left ovary (arrows) and in the medulla of the right gonad (arrows). Scale bar in whole mounts $=1 \mathrm{~mm}$, scale bar in tissue sections $=100 \mu \mathrm{m}$. 

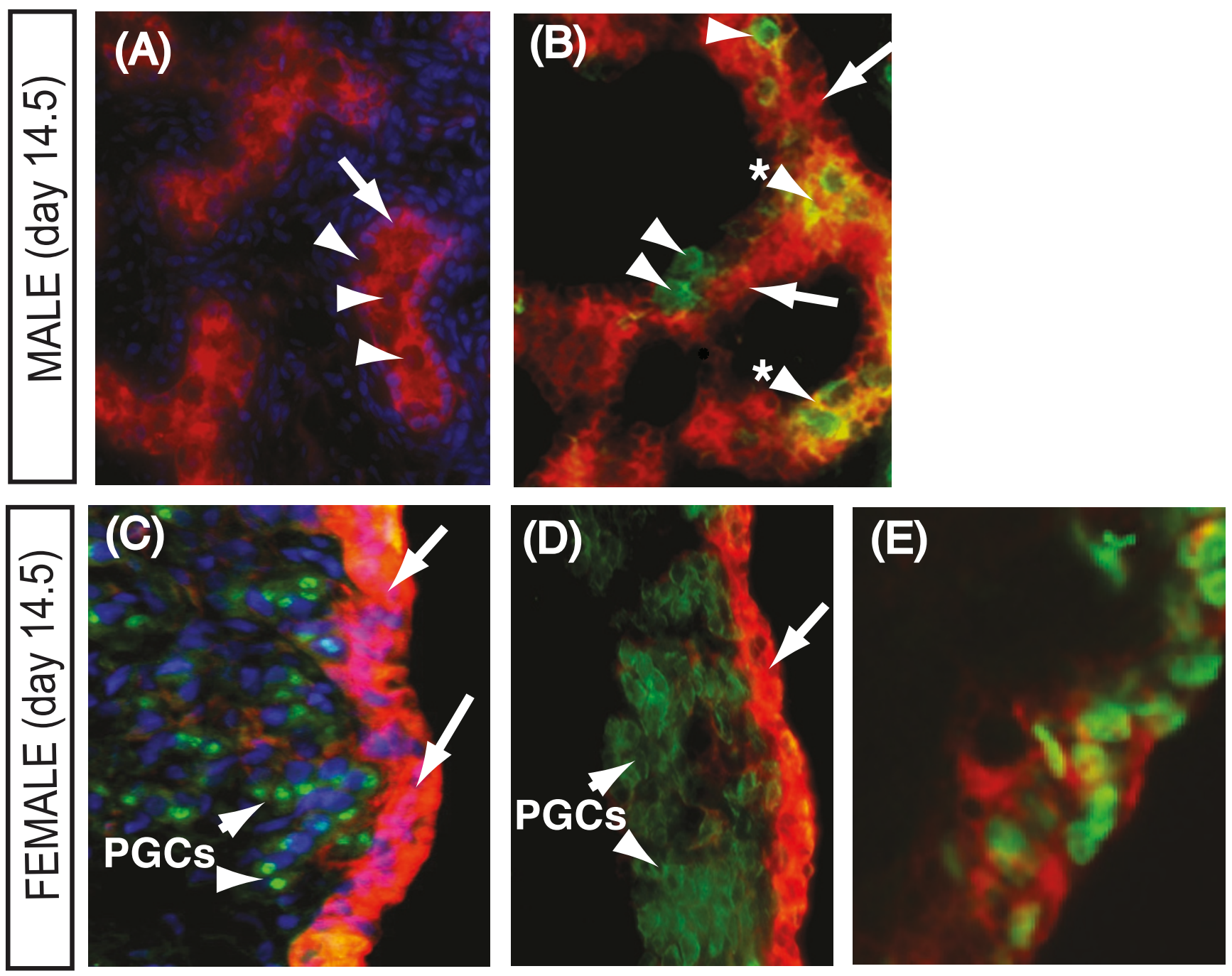

Figure 7

Localisation of RALDH2 enzyme in day $\mathbf{4} .5$ male and female embryonic chicken gonads. (A) In males, RALDH2 (arrows; red) localises in Sertoli cells of seminiferous cords. DAPI-stained nuclei delineate germ cells that appear negative for RALDH2 (arrowheads). (B) Double staining with the germ cell marker, GCNA, shows RALDH2 is somatic cells (Sertoli cells; red), but not in many germ cells (arrowheads, green). Some germ cells appear to stain for both proteins (yellow; asterisked arrowheads). (C) RALDH2 expression in somatic (pre-follicular) cells of the left cortex (arrows; red). SOX2+ germ cells (arrowheads; green) are negative for RALDH2. (D) Double-staining of the left ovarian cortex, showing an outer zone of RALDH2+ somatic cells (red; arrows) and underlying germ cells that are GCNA+ (PGCs; arrowheads; green). (E) Double staining of cortical somatic cells reveals GATA4+ nuclei (green) in cells that are also positive for RALDH2 in the cytoplasm (red). 

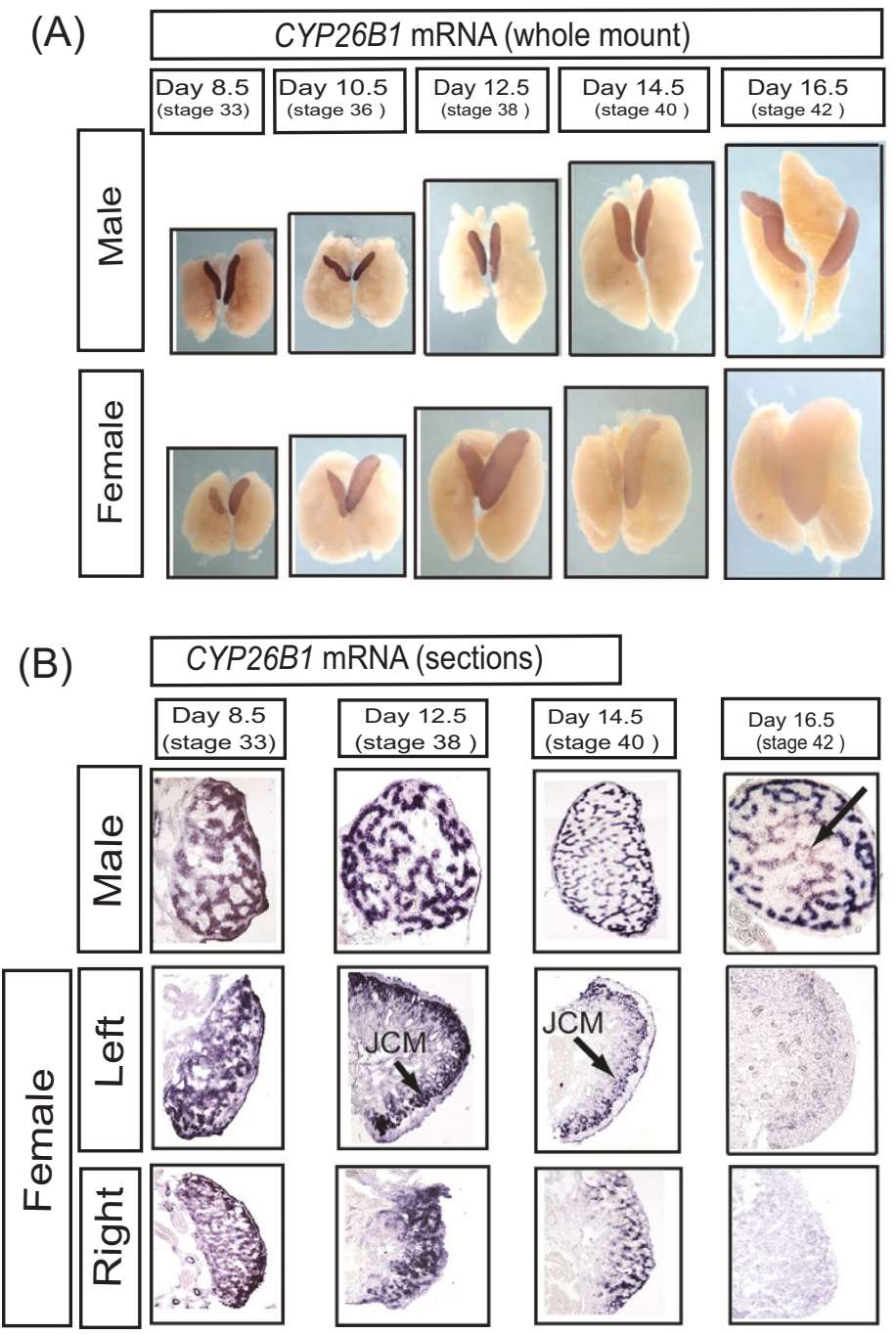

\section{Figure 8}

Expression of CYP26BI mRNA during gonadal development in chicken embryos, assessed by whole mount in situ hybridisation. (A) In males, CYP26BI is strongly expressed in both gonads, and not in mesonephric kidneys, throughout development. In females, expression is initially strong in both gonads, but declines from day I4.5. (B) In males, CYP26BI expression localises to seminiferous cords in developing testes (arrow). In females, CYP26BI is initially expressed in the medulla of both gonads, but becomes concentrated in the juxtacortical medulla (JCM) from day 12.5 , and expression declines thereafter. The left cortex is always negative for CYP26BI (e.g., arrow at 16.5). In the right gonad, expression persists in the medulla overdevelopment, declining at later stages.

served role for retinoic acid in regulating entry into meiosis. In vivo histology and in vitro experiments conducted over thirty years ago indicated that female germ cells enter meiotic prophase during embryogenesis in birds, as occurs in mammals [24-26]. These early studies variably reported that meiosis in the left female chicken gonad commences on day $14,15,16,17$ or 18 of development $[14,15,27]$. We have found that chicken STRA8 is up-regulated specifically in the left female gonad from day 12.5 , as assessed by qRT-PCR, and meiosis is detectable by SCP3 immunostaining in some cells at day 15.5, becoming widespread at day 16.5 and 17.5 (Fig. 2). This indicates that entry into meiosis is not a synchronous event in the chicken embryo, but occurs over a number of days. This has been reported previously, in a detailed study on the stages of meiosis in the germ cells of the left female gonad [14]. Therefore, while some cells may be entering meiotic prophase, others are still undergoing mitosis. Indeed, it has been reported that the germ cell population as a whole is still proliferating up to day 17 [25]. This implies 
(A)

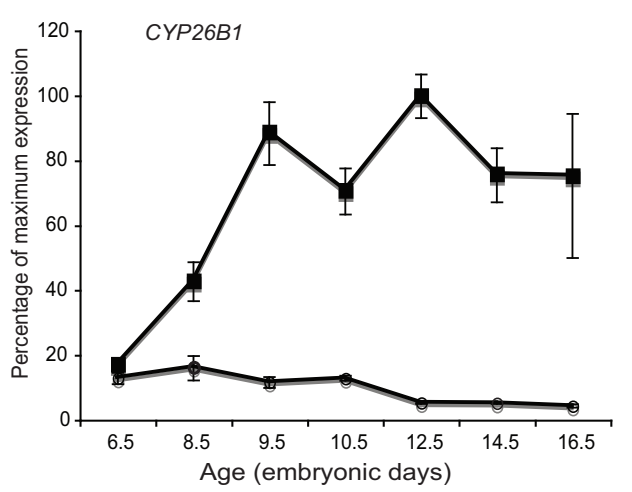

(B)

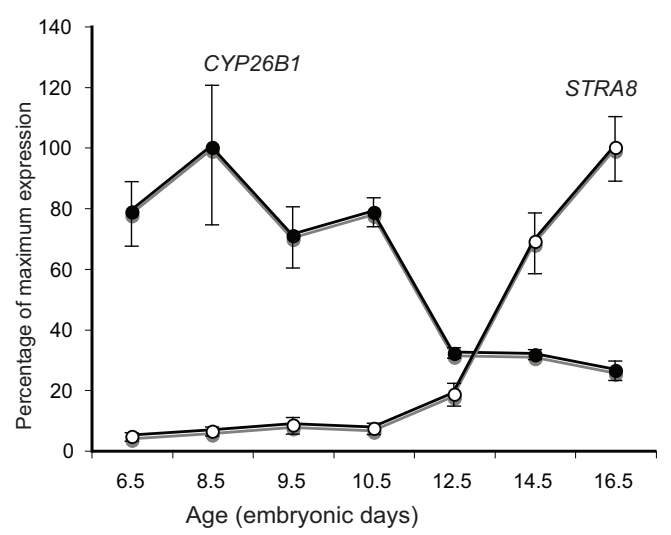

Figure 9

Expression of CYP26BI mRNA in embryonic chicken gonads, assessed by real time PCR (qRT-PCR). (A) CYP26BI expression is up-regulated in male gonads from day 8.5 (closed squares). In female gonads (left and right pooled) there is initially a low level of expression, relative to males. From day 10.5, expression declines in females (open circles). (B) Gonadal expression profiles of CYP26BI (closed circles) and STRA8 (open circles) in female chicken embryos, analysed together. An inverse relationship is evident; when CYP26BI expression declines from day 10.5, STRA8 expression is up-regulated.

that the signal for meiosis in the female chicken embryo is activated asynchronously in the germ cell population. In the mouse embryo, there is a anterior to posterior wave of meiosis in the female gonad over $24-48$ hours $[8,28]$. However, this was not observed in the chicken (Fig's 2 and 3).

In contrast to the mouse, germ cell meiosis in the female chicken embryo occurs well after the onset of somatic gonadal sex differentiation, which begins at day 6 (stage 29) [22]. Ovarian differentiation is well advanced by the time that SCP3 protein is first detectable by immunofluorescence (day 15.5). Therefore, somatic commitment and meiosis are significantly separated in time. This is an inter- esting difference between chicken and mouse. Byskov [29] recognised mammals with so-called "immediate" versus "delayed" meiosis. In some species, meiosis occurs "immediately" at the time of somatic gonadal sex differentiation (such as the mouse), while meiosis is "delayed" in others, occurring after the onset of somatic differentiation (as in humans and rabbits). The chicken embryo would fall into the so-called "delayed" meiosis group. The reasons for this delay are unclear, although the germ cells could become committed to the female pathway at the molecular level at the time of gonadal sex differentiation in so-called "delayed" species, only showing morphological signs later in development. In the chicken and in other species, an aggregation of mitochondria occurs around the Golgi, called the Balbiani body, well prior to meiosis. In the chicken embryo, the Balbiani body is first detected in some female germ cells at day 7 , and in many at day 10 [25], implying commitment to the female pathway shortly after the onset of gonadal sex differentiation (day 6). (A Balbiani body has recently been described in neonatal mouse oocytes; [30]).

In the female chicken embryo, it has been reported that pre-meiotic DNA synthesis begins in the germ cells of the left gonad between days 15 and 16 [31]. In the mouse, Stra8 is required for the pre-meiotic DNA synthesis that precedes meiosis [9]. Cloning and expression of chicken STRA8 revealed female-specific expression in the left ovarian cortex from day 12.5, prior to the onset of meiosis. This expression pattern suggests that, as in mouse, STRA 8 is expressed in pre-meiotic germ cells and plays a role in meiotic induction in females. Notably, no STRA8 expression was detectable in the right female gonad, consistent with a lack of meiotic germ cells there. The organ culture studies described here indicate that germ cells in the left female gonad can enter meiosis normally at day 15.5 when explanted at day 10.5 and cultured in serum-free basal medium. This indicates that either the germ cells enter meiosis cell autonomously according to an intrinsic clock, or that a signal for meiosis is sent at or before the time of culture (day 10.5).

It has been shown that retinoic acid triggers meiosis in female mouse embryos. In the study described here, we also find evidence of retinoic acid involvement in regulating avian meiosis. In the chicken embryo, RALDH2 and CYP26B1 are major enzymes of retinoic acid synthesis and degradation, respectively $[23,32,33]$. Embryonic chicken tissues that express RALDH2 have been shown to possess retinoic acid synthesising activity $[32,34]$. $R A L D H 2$ is therefore a robust indicator of retinoic acid synthesis in the chicken embryo, as in the mouse. Similarly, CYP26B1 expression reflects sites of retinoic acid catabolism [35]. Generally, RALDH2 and CYP26B1 are expressed in a co-ordinated fashion, usually in compli- 


\section{Retinoic acid receptor- $\beta$ mRNA (whole mount)}

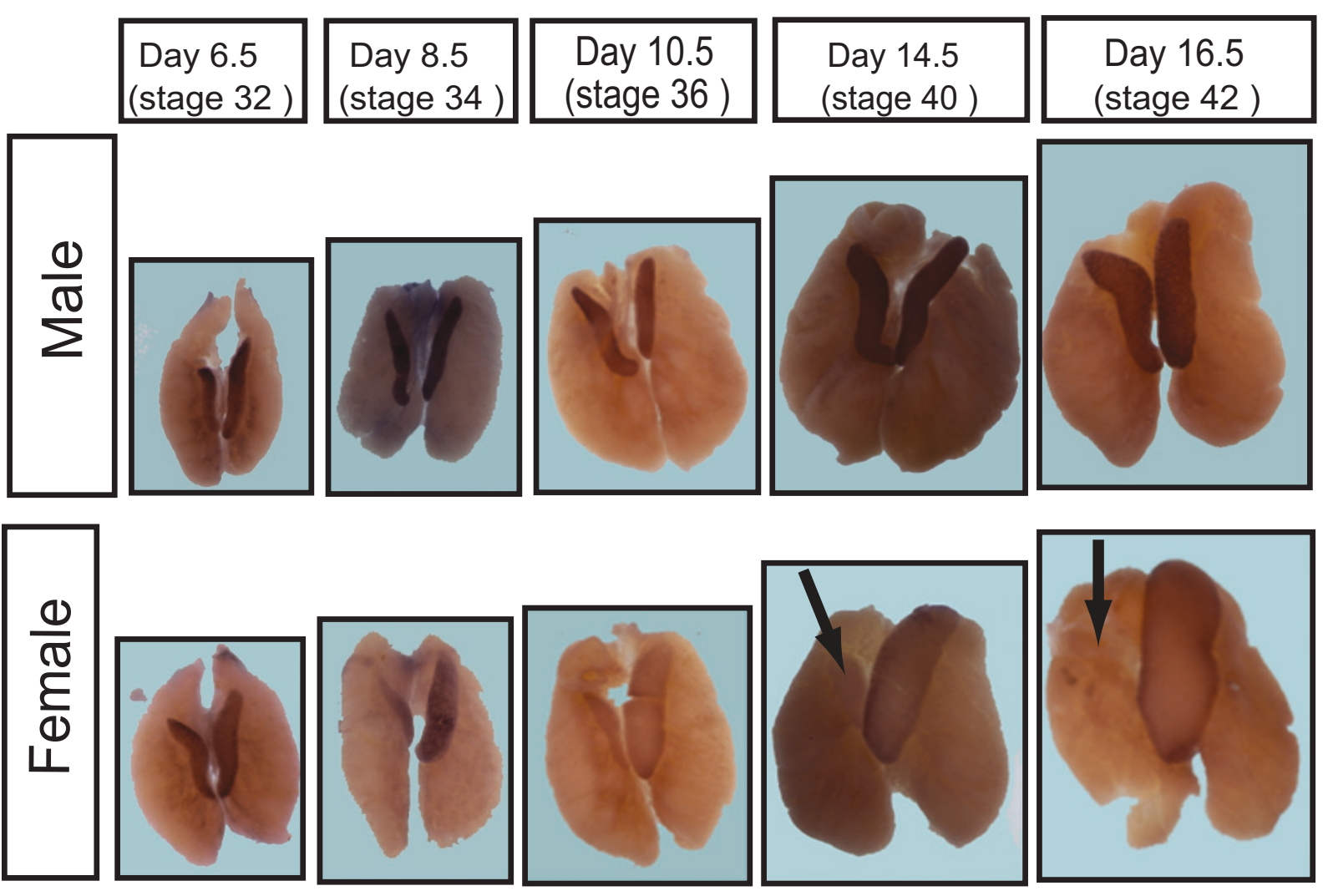

Figure 10

Expression of Retinoic acid receptor $\beta(\operatorname{RAR} \beta)$ during gonadal development in chicken embryos, assessed by whole mount in situ hybridisation. RAR $\beta$ is expressed in both gonads of both sex throughout development, except in females, where expression declines in the right gonad (arrow).

mentary domains that result in localised patterns of retinoic acid action (where RALDH2 is expressed, CYP26B1 is not, and vice versa). The study reported here is the first detailed description of genes encoding retinoic acid metabolising enzymes in the embryonic gonads of an avian species. Furthermore, we find dynamic expression patterns that implicate retinoic acid signaling in avian meiosis, as in the mouse. Figure 11 summarises the expression of RALDH2 and CYP26B1 in relation to the initiation of meiosis in the chicken embryo. The two enzymes are strongly co-expressed in the developing testis, potentially leading to retinoic acid synthesis and degradation, with no accumulation of retinoic acid to influence germ cells. This is despite the strong expression of RAR- $\beta$ throughout development in males. In the female, RALDH2 expression is maintained in the left gonad and CYP26B1 is down-regulated after day 10.5, pointing to an accumulation of retinoic acid prior to and at the time of STRA8 induction (Fig. 9B and Fig. 11). In the right female gonad, where only a medulla is present, both RALDH2 and CYP26B1 are expressed. This would lead to a degradation of retinoic acid, and indeed no meiosis is seen in the right gonad. Similarly, a small number of germ cells in the left female gonad remain scattered in the CYP26B1+ medulla (GCNA+ cells seen in Fig. 2). These germ cells also do not enter meiosis (Fig 2). These 
Table I: Dynamic expression of genes involved in retinoic acid synthesis and degradation in embryonic chicken gonads.

\begin{tabular}{|c|c|c|c|c|c|c|c|}
\hline \multicolumn{5}{|c|}{ Retinoic acid degradation } & \multicolumn{3}{|c|}{ Meiosis $\Rightarrow$} \\
\hline Gene & Sex & Day 6.5 (stage 3I) & Day 8.5 & Day 10.5 & Day I2.5 (stage 38$)$ & Day 14.5 & Day 16.5 \\
\hline \multirow[t]{2}{*}{ RALDHI } & Female & - & - & - & - & - & - \\
\hline & Male & - & ++ & +++ & +++ & +++ & +++ \\
\hline \multirow[t]{2}{*}{$\mathrm{RALDH} 2$} & Female & ++ & +++ & +++ & +++ & +++ & +++ \\
\hline & Male & +++ & +++ & +++ & +++ & +++ & +++ \\
\hline \multirow[t]{2}{*}{ RALDH3 } & Female & - & - & - & - & - & - \\
\hline & Male & - & +++ & +++ & +++ & - & - \\
\hline \multicolumn{5}{|c|}{ Retinoic acid degradation } & \multicolumn{3}{|c|}{ Meiosis $\Rightarrow$} \\
\hline Gene & Sex & Day 6.5 (stage 3I) & Day 8.5 & Day 10.5 & Day I2.5 (stage 38) & Day 14.5 & Day 16.5 \\
\hline \multirow[t]{2}{*}{ CYP26AI } & Female & + & - & - & - & - & - \\
\hline & Male & - & - & - & - & - & - \\
\hline \multirow[t]{2}{*}{ CYP26BI } & Female & +++ & +++ & +++ & +++ & + & - \\
\hline & Male & +++ & +++ & +++ & +++ & +++ & +++ \\
\hline \multirow[t]{2}{*}{ CYP26CI } & Female & + & - & - & - & - & - \\
\hline & Male & - & - & + & + & - & - \\
\hline
\end{tabular}

Expression is based on whole mount in situ hybridisation. Overall level of gene expression was reflected in staining intensity; -not expressed, + lowly expressed; +++ strongly expressed. The onset of meiosis in females (SCP3 protein expression) is indicated by arrow.

expression patterns in the female support a role for retinoic acid in initiating meiosis.

However, RALDH2 expression was detectable in the left cortex of female gonads from early stages (at day 8.5 and day 10.5; figure 6B). Germ cells accumulate in the RALDH2+ left cortex as it proliferates at theses early stages, while STRA8 up-regulation is first detectable by qRT-PCR at day 12.5. The discrepancy in timing between cortical RALDH2 and STRA8 expression could indicate that retinoic acid acts indirectly to induce meiosis. Retinoic acid may set in motion a series of molecular events that result in STRA8 induction (In the mouse, it is assumed that retinoic acid directly activates Stra 8 gene expression, but this has not been definitively shown). Embryonic chicken ovaries explanted in basal serum-free medium at day 10.5 could still initiate meiosis, implying that commitment to the female pathway had already occurred at the time of explantation. This commitment could be mediated by the early synthesis of retinoic acid in the developing cortex.

An alternative possibility is that is that retinoic acid synthesised by RALDH2 in the cortex is preferentially targeted to the underlying juxtacortical medulla, the site of CYP26B1 expression, bypassing the germ cells. In early stages (up to day 12.5), this would result in retinoic acid degradation, but, at later stages, loss of CYP26B1 expression would make retinoic acid available to the germ cells. Differential expression of retinoic acid receptors could be the mechanism for regulating the bioavailablity of retinoic acid to germ cells. We found that RAR- $\beta$ is expressed in both sexes over development, with stronger expression males. The significance of RAR- $\beta$ expression in males is unclear, but it is assumed that all synthesised retinoic acid is degraded. Despite the lower RAR- $\beta$ expression in the left female gonad, differential RAR- $\beta$ expression could mediate the timing of retinoic acid action. The precise sites of RAR expression within developing gonads were not examined here, but future studies should address this point.

Figure 12 compares gene expression in chicken and mouse embryonic gonads in relation to meiosis. Unlike the mouse embryo, in which Raldh2 is expressed in the adjoining mesonephric kidneys, chicken RALDH2 is expressed predominantly in the gonads themselves. In the male gonad, both RALDH2 and CYP26B1 are expressed in the developing seminiferous cords at all stages examined, from day 6.5 to day 16.5. Immunofluorescence confirmed Sertoli cell expression for RALDH2. Therefore, the seminiferous cords are expected to both synthesise and degrade retinoic acid, preventing it from influencing germ cells (Fig 12). Retinoic acid has been shown to be a potent stimulator of CYP26B1 gene expression in the chicken embryo [35], which would provide a mechanism of negative auto-regulation in the seminiferous cords. RALDH2 is also expressed throughout development in female gonads, initially in the medulla of both left and right gonads, but becoming concentrated in the proliferating cortex of the left gonad. This is the site of meiosis. In contrast, in the left female gonad, CYP26B1 expression becomes localised to the juxtacortical medulla - but never in the cortex. Therefore, in the left female gonad, retinoic acid synthesised but not degraded in the cortex could regulate entry of cortical germ cells into meiosis, either directly or indirectly (Fig. 12). In the mouse, Cyp26b1 is 


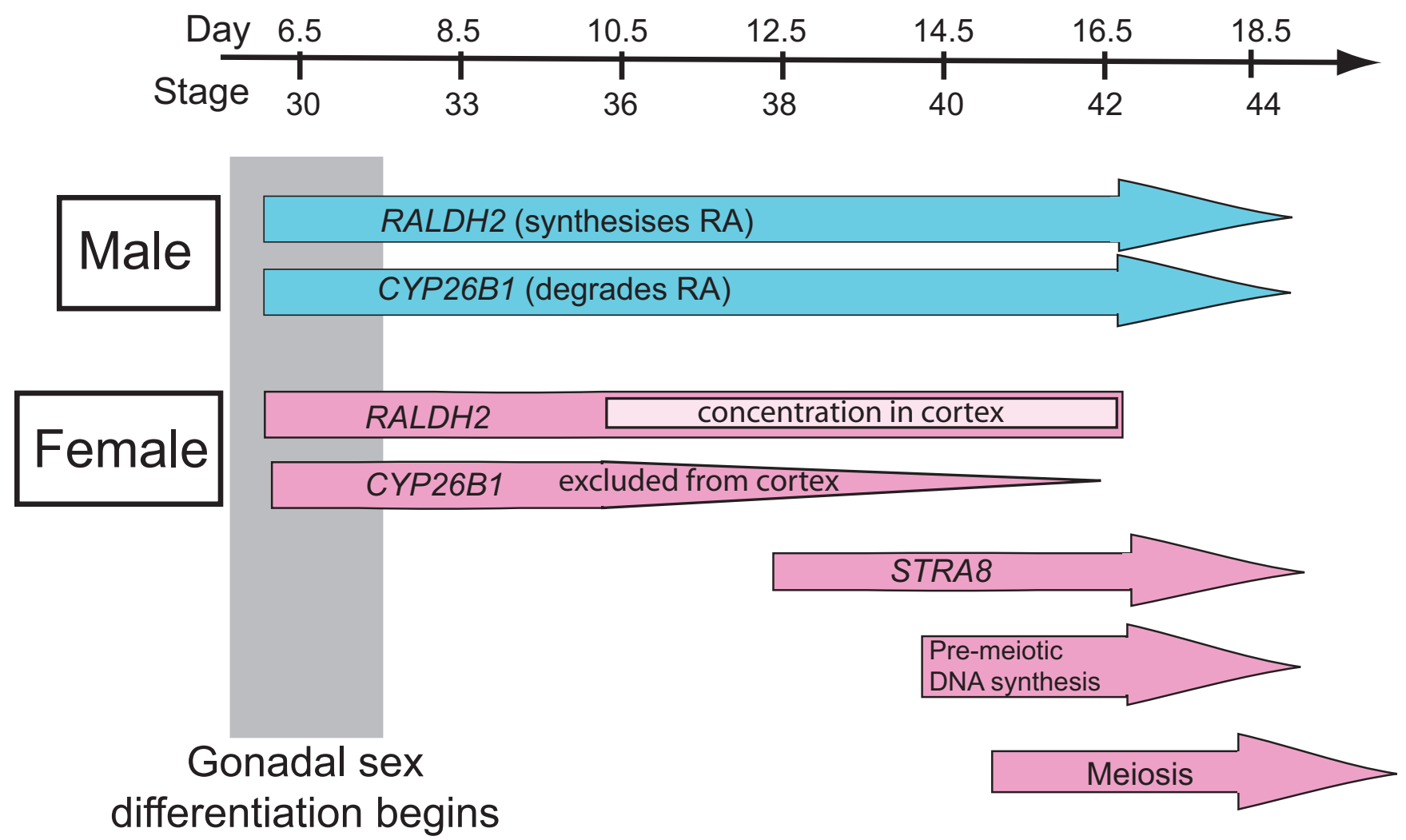

Figure I I

Timing of meiosis and retinoic acid metabolism during gonadal development in chicken embryos. Male shown in blue, female shown in pink. Gonadal sex differentiation begins at day 6.0. In the male gonads, RALDH2 and CYP26BI are both highly expressed and meiosis does not occur during embryogenesis. In the left female gonad, RALDH2 is highly expressed, becoming concentrated in the cortex as it proliferates. CYP26BI expression is down-regulated after EI0.5, and is excluded form the cortex. At EI2.5, STRA8 is up-regulated in the left gonad, and, at, EI5, pre-meiotic DNA synthesis begins [3I]. Meiosis is detectable histologically from EI5.5.

extinguished completely in female gonads at the time of meiosis.

In the female chicken embryo, the fate of germ cells is dictated by their location; those in the cortex of the left gonad enter meiosis, while those in the right gonad and those in the left medulla fail to enter meiosis. This indicates that a somatic signal, rather than cell autonomous mechanism, regulates entry into meiosis in the chicken embryo. The asymmetry of germ cell fate in the female chicken embryo therefore provides a unique system for testing the regulation of meiosis. If retinoic acid plays a role in avian meiosis, some aspect of retinoic acid metabolism is expected to show asymmetry between the left and right gonads. This asymmetry is evidently achieved by proliferation of a thickened ovarian cortex in the left gonad, which strongly expresses $R A L D H 2$ but not CYP26B1. In the left gonad, germ cells become concentrated in this cortical environment. In contrast, germ cells of the right gonad and the left medulla are "stranded" in an environment expressing
CYP26B1, potentially leading to degradation of retinoic acid (Fig. 12). Germ cells would therefore not enter meiosis. Indeed, it has been shown that germ cells in the right gonad of female chicken embryos undergo cell death [36]. In males, an unidentified signal from the somatic cells is presumed to induce mitotic arrest, as occurs in mouse. This signal is presumably absent in the both the right and left female chicken gonads.

The data presented here indicate the left ovarian cortex is critical for meiosis in female chicken embryos. This is supported by previous organ culture experiments. Erickson [25] cultured whole female embryonic gonads, isolated pieces of cortex, or groups of pure germ cells. Germ cells entered meiosis when present in the intact gonads, in isolated cortex, and when isolated and co-cultured with pieces of cortex, but not when isolated and cultured alone. It was concluded that "the differentiation of female germ cells is regulated by the somatic cells of the cortex" [25]. The data presented here support this conclusion and sug- 


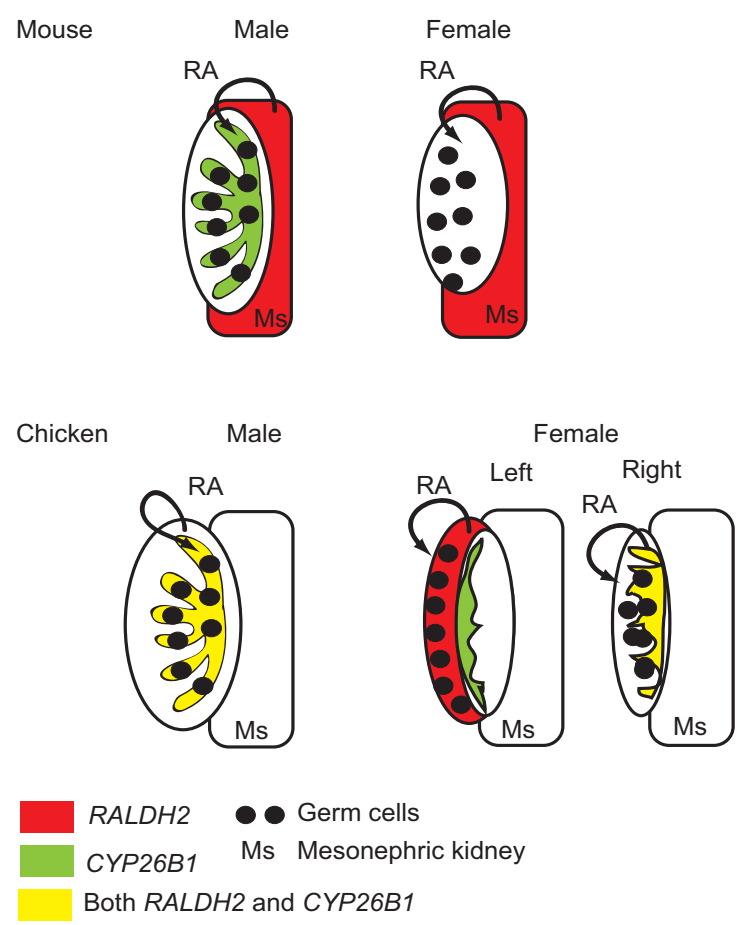

Figure 12

A comparison of retinoic acid metabolism in the embryonic urogential system of the mouse and chicken.RALDH2-expressing tissue is shown in red, CYP26Bl-expressing tissue is shown in green; tissues expressing both enzyme mRNAs are shown in yellow. In the mouse at EI2.5, Raldh2 is expressed in the mesonephric kidney, retinoic acid then enters the gonad and in males, is degraded by Cyp26bl. In females, Cyp26bl is absent, allowing retinoic acid to induce germ cells meiosis. In the chicken at EI 4.5, the gonads of both sexes express RALDH2. In males, RALDH2 and CYP26BI are co-expressed in seminiferous cords. In the cortex of the left female gonad, where germ cells are located, RALDH2 is expressed but CYP26BI is not (CYP26BI expression is localised at the border between the cortex and medulla). In the right gonad, as in the testis, both $R A L D H 2$ and CYP26BI are expressed, potentially leading to retinoic acid degradation and no meiosis.

gest that retinoic acid is the factor associated with the somatic cells of the cortex. The organ culture experiments conducted here indicate that germ cells commit to the female pathway at or prior to day 10.5 (the time of explantation in serum-free basal medium). This is consistent with the proliferation of a $\mathrm{RALDH} 2+$ cortex at this time (Fig. 11).

An alternative possibility is that germ cells enter meiosis cell-autonomously in birds. In a previous study, primordial germ cells were isolated from quail blastoderms and introduced into very young (day 3 ) chicken embryos in ovo. These quail germ cells populated the chicken embry- onic gonads and entered meiosis according to the quail timetable (meiotic figures from day 12.5) rather than the chicken timetable (meiotic figures from day 15.5) [37]. This suggested that meiosis follows an endogenous clock in avian (quail) germ cells. However, as mentioned above, the left-right asymmetry of germ cell fate in the female chicken embryo argues for differential somatic signals rather than a cell autonomous mechanism. An alternative interpretation of the quail transplantation experiment is that retinoic acid from the chicken gonad is able to induce meiosis in the quail cells because they are responsive to it at an earlier time than the endogenous chicken germ cells.

This study presents the first detailed analysis of meiosis onset in avian embryos. We provide circumstantial evidence that retinoic acid has a conserved role in regulating entry into meiosis, at least in higher vertebrates. Further studies are now required to test this possible role for retinoic acid in avian meiosis. Such studies should include an examination of meiosis in isolated germ cells or in whole gonads cultured in the presence of retinoic acid or its inhibitors.

\section{Abbreviations}

BSA: Bovine serum albumen; CHAPS: 3-[(3-Cholamidopropyl) dimethyl-ammonio]-1-propane sulfonate; CYP26: Cytochrome p450 from family 26; FCS: foetal calf serum; GCNA: germ cell nuclear antigen; NTMT: sodium chloride: Tris base: magnesium chloride with Tween 20; RALDH: Retinaldehyde dehydrogenase; qRT-PCR: quantitative reverse transcription and polymerase chain reaction; RT-PCR: Reverse transcription and polymerase chain reaction; SCP3: Synaptonemal complex 3; STRA8: Stimulated by Retinoic Acid gene 8.

\section{Authors' contributions}

CAS and JB designed the study, while CAS and KNR carried out the experiments (CAS performed the immunofluorescence, the organ culture, and some of the whole mount in situ hybridisation experiments. KNL carried out whole mount in situ hybridisation and quantitative real time PCR experiments). CAS, KNR, JB, PK and AHS prepared the manuscript. All authors read and agreed with the final draft.

\section{Acknowledgements}

We thank Dr. Malcolm Madden, King's College, London, for the chicken RALDH and CYP26 riboprobes, and Dr. Patrick Western for helpful comments on the manuscript. This work was supported by the Australian Research Council.

\section{References}

I. McLaren A: Primordial germ cells in the mouse. Dev Biol 2003, 262:1-15

2. McLaren A, Southee D: Entry of mouse embryonic germ cells into meiosis. Dev Biol 1997, 187:107-13. 
3. Zamboni L, Upadhyay S: Germ cell differentiation in mouse adrenal glands. J Exp Zool 1983, 228: 173-93.

4. Chuma S, Nakatsuji N: Autonomous transition into meiosis of mouse fetal germ cells in vitro and its inhibition by gp/30. mediated signaling. Dev Biol 200I, 229:468-79.

5. Bowles J, Knight D, Smith C, Wilhelm D, Richman J, Mamiya S, Yashiro K, Chawengsaksophak K, Wilson MJ, Rossant J, et al.: Retinoid signaling determines germ cell fate in mice. Science 2006, 3 I 2:596-600.

6. Koubova J, Menke DB, Zhou Q, Capel B, Griswold MD, Page DC: Retinoic acid regulates sex-specific timing of meiotic initiation in mice. Proc Natl Acad Sci USA 2006, 103:2474-9.

7. Haselbeck RJ, Hoffmann I, Duester G: Distinct functions for Aldh I and Raldh2 in the control of ligand production for embryonic retinoid signaling pathways. Dev Genet 1999, 25:353-64.

8. Menke DB, Koubova J, Page DC: Sexual differentiation of germ cells in XX mouse gonads occurs in an anterior-to-posterior wave. Dev Biol 2003, 262:303-12.

9. Baltus AE, Menke DB, Hu YC, Goodheart ML, Carpenter AE, de Rooij DG, Page DC: In germ cells of mouse embryonic ovaries, the decision to enter meiosis precedes premeiotic DNA replication. Nat Genet 2006, 38:1430-4.

10. Oulad-Abdelghani M, Bouillet P, Decimo D, Gansmuller A, Heyberger S, Dolle P, Bronner S, Lutz Y, Chambon P: Characterization of a premeiotic germ cell-specific cytoplasmic protein encoded by Stra8, a novel retinoic acid-responsive gene. J Cell Biol I996, 135:469-77.

II. Bowles J, Koopman P: Retinoic acid, meiosis and germ cell fate in mammals. Development 2007, I34:340 I-II.

12. Fujimoto $T$, Ukeshima $A$, Kiyofuji R: The origin, migration and morphology of the primordial germ cells in the chick embryo. Anat Rec 1976, I 85: 139-45.

13. Mendez C, Carrasco E, Pedernera E: Adenohypophysis regulates cell proliferation in the gonads of the developing chick embryo. J Exp Zoolog A Comp Exp Biol 2005, 303: 179-85.

14. Hughes GC: The population of germ cells in the developing female chick. I Embryol exp Morph 1963, I I:5 I3-536.

15. Ukeshima A, Fujimoto T: A fine morphological study of germ cells in asymmetrically developing right and left ovaries of the chick. Anat Rec 1991, 230:378-86.

16. Hamburger $\mathrm{V}$, Hamilton HL: A series of normal stages in the development of the chick embryo. J Morph I95I, 88:49-92

17. Clinton M, Haines L, Belloir B, McBride D: Sexing chick embryos: a rapid and simple protocol. Br Poult Sci 200I, 42:I34-8.

18. Reijnties S, Gale E, Maden M: Generating gradients of retinoic acid in the chick embryo: Cyp26Cl expression and a comparative analysis of the Cyp26 enzymes. Dev Dyn 2004, 230:509-17.

19. Andrews JE, Smith CA, Sinclair AH: Sites of estrogen receptor and aromatase expression in the chicken embryo. Gen Comp Endocrinol 1997, 108: 182-90.

20. Smith CA, McClive PJ, Hudson QJ, Sinclair AH: Male-specific cell migration into the developing gonad is conserved between mammals and birds and involves PDGF signalling. Developmental Biology 2005 in press.

21. Smith $C A$, Sinclair $A H$ : Sex determination: insights from the chicken. Bioessays 2004, 26: 120-32.

22. Smith CA, Katz M, Sinclair AH: DMRTI is upregulated in the gonads during female-to-male sex reversal in $\mathrm{ZW}$ chicken embryos. Biol Reprod 2003, 68:560-70.

23. Swindell EC, Thaller C, Sockanathan S, Petkovich M, Jessell TM, Eichele G: Complementary domains of retinoic acid production and degradation in the early chick embryo. Dev Biol 1999 216:282-96.

24. Wylie CC: Nuclear morphology and nucleolar DNA synthesis during meiotic prophase in oocytes of the chick (Gallus domesticus). Cell Differ 1972, I:325-34.

25. Erickson GF: The control of the differentiation of female embryonic germ cells in the bird. Dev Biol 1974, 36: I I3-29.

26. Swift C: Origin and early history of the primordial germ cells of the chick. Am J Anat 19|4, 20:375-410.

27. Civinini $A$, Mastrolia $L$ : Ultrastructural localization of acid phosphatase in germ cells of chick embryo left ovary. Exp Cell Bio 1986, 54:94-105.
28. Bullejos M, Koopman P: Germ cells enter meiosis in a rostrocaudal wave during development of the mouse ovary. Mol Reprod Dev 2004, 68:422-8.

29. Byskov G: Differentiation of the mammalian embryonic gonad. Physiol Rev 1986, 66:7I-II7.

30. Pepling ME, Wilhelm JE, O'Hara AL, Gephardt GW, Spradling AC: Mouse oocytes within germ cell cysts and primordial follicles contain a Balbiani body. Proc Natl Acad Sci USA 2007, 104:187-92.

31. Callebaut M: Premeiosis and premeiotic DNA synthesis in the left ovary of the female chick embryo. J Embryol Exp Morphol 1967, 18:299-304.

32. Berggren K, McCaffery P, Drager U, Forehand Cl: Differential distribution of retinoic acid synthesis in the chicken embryo as determined by immunolocalization of the retinoic acid synthetic enzyme, RALDH-2. Dev Biol 1999, 210:288-304.

33. Blentic $A$, Gale $E$, Maden $M$ : Retinoic acid signalling centres in the avian embryo identified by sites of expression of synthesising and catabolising enzymes. Dev Dyn 2003, 227: | | 4-27.

34. Maden M, Sonneveld E, Saag PT van der, Gale E: The distribution of endogenous retinoic acid in the chick embryo: implications for developmental mechanisms. Development 1998, 125:4133-44.

35. Reijntjes S, Gale E, Maden M: Expression of the retinoic acid catabolising enzyme CYP26BI in the chick embryo and its regulation by retinoic acid. Gene Expr Patterns 2003, 3:62I-7.

36. Ukeshima A: Germ cell death in the degenerating right ovary of the chick embryo. Zoolog Sci 1996, I3:559-63.

37. Dieterlen-Lievre F, Martin C, Hajii K: A time clock for meiosis initiation is programmed in avian germ cells. Prog Clin Biol Res 1986, 217A:183-6.
Publish with Bio Med Central and every scientist can read your work free of charge

"BioMed Central will be the most significant development for disseminating the results of biomedical research in our lifetime. "

Sir Paul Nurse, Cancer Research UK

Your research papers will be:

- available free of charge to the entire biomedical community

- peer reviewed and published immediately upon acceptance

- cited in PubMed and archived on PubMed Central

- yours - you keep the copyright
BiolMedcentral 